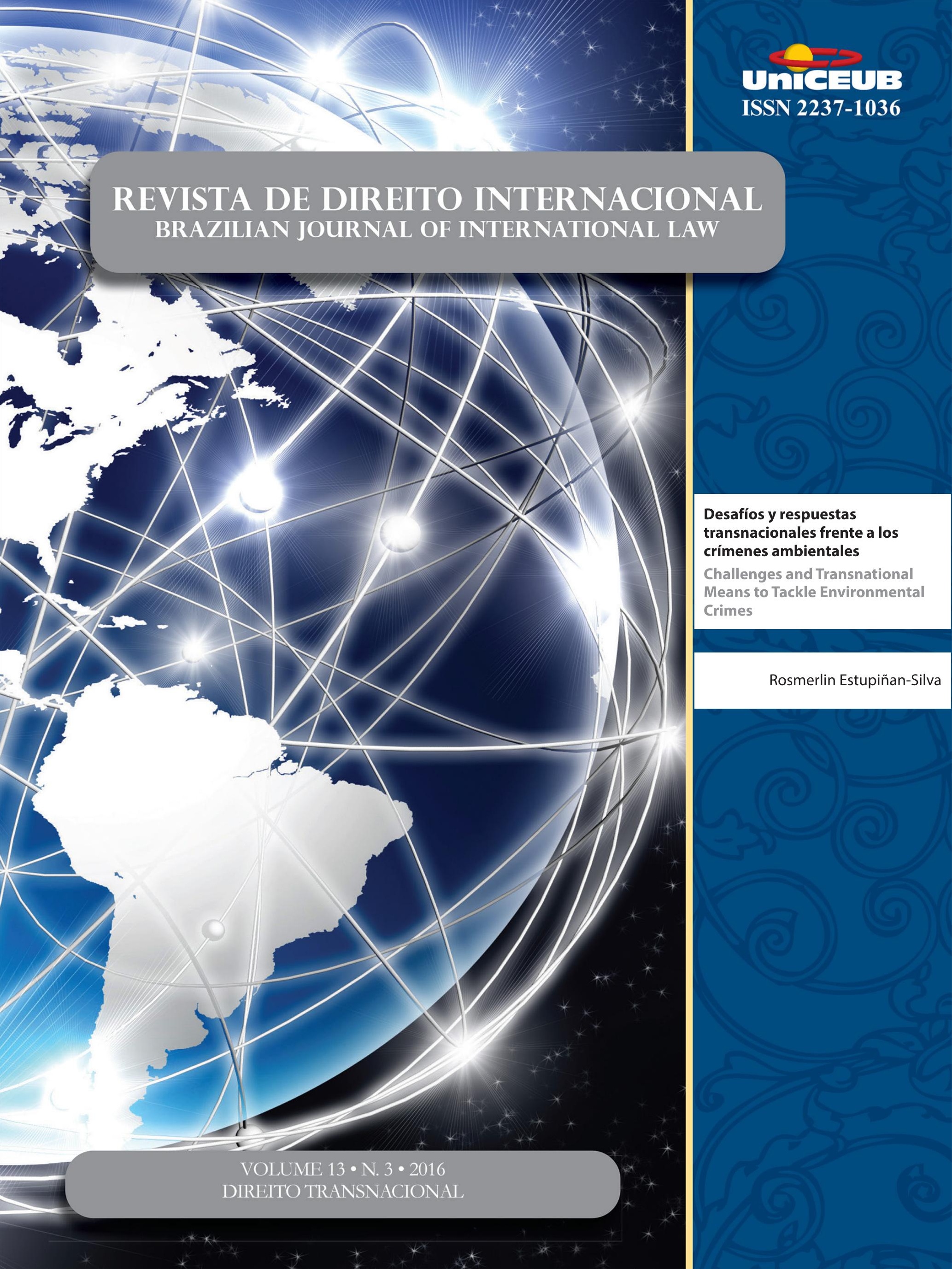


Crônicas da ATUALIdAde do direito internacional .................................................. 2

I. Dossiê Temático: Direito Transnacional .........................................................15

EDITORIAL: O Direito Transnacional - Circulação de normas e relações jurídicas transnacionais .......16 Priscila Pereira de Andrade

A emergênCia do direito transnacional ambiental .............................................18 Priscila Pereira de Andrade

Desafíos y RESPUESTAS TRANSNACIONALES FRENTE A LOS CRÍMENES AMBIENTALES ...............30 Rosmerlin Estupiñan-Silva

DiREITO TRANSNACIONAL E MUdANÇAS CLIMÁTICAS .50 Géraud de Lassus Saint-Geniès

Especies en movimiento: la Convención sobre el Comercio Internacional de Especies Amenazadas de Fauna y Flora Silvestres como espacio de “Encuentro” de discursos, ACTORES Y ESTRATEGIAS EN EL DERECHO AMBIENTAL TRASNACIONAL

María Valeria Berros e Dabel Leandro Franco

El carácter transnacional del Sistema comunitario de ECogestion « Eco-ManageMENT AND Audit SCHEME » (EMAS) DENTRo de LA UE y MÁs ALlÁ DE SUS Fronteras ......72 Adélie Pomade

O CONCEITO DE CONDUTA EMPRESARIAL RESPONSÁVEL À LUZ DOS ORDENAMENTOS JURÍDICOS BRASILEIRO, INTERNACIONAL E TRANSNACIONAL

Gabriel Webber Ziero

ARBITRAGEM NO DIREITO TRIBUTÁRIO INTERNACIONAL E NO DIREITO INTERNACIONAL DOS INVESTIMENTOS: UMA MANIFESTAÇÃO DO DIREITO TRANSNACIONAL

Vivian Daniele Rocha Gabriel 
O DIREITO TRIBUTÁRIO SOB UMA PERSPECTIVA TRANSNACIONAL

Franciele de Simas Estrela Borges

As Características do Direito Transnacional como Metodologia: Análise sob o enfoQue dos Aspectos Processuais da Arbitragem 126

Flávia Foz Mange

O DIREITO TRANSNACIONAL (“GLOBAL LAW") E A CRISE DE PARADIGMA DO ESTADO-CENTRISMO: É POSSÍVEL CONCEBER UMA ORDEM JURÍDICA TRANSNACIONAL? ...................................... 146

Luiza Nogueira Barbosa e Valesca Raizer Borges Moschen

TransPorte AÉREO E DIREITO TRANSNACIONAL: DA CONVERGÊNCIA À UNIFORMIDADE 160 Mickael R. Viglino

Outros Artigos. 175

O Fundo Monetário Internacional e a proteção dos direitos humanos: uma análise DO PROGRAMA DE CRESCIMENTO E REDUÇÃO DA POBREZA NO HAITI 177

Pablo Henrique Hubner de Lanna Costa e Carlos Alberto Simões de Tomaz

Um estranho no ninho? Padrões privados no Acordo de Barreiras Técnicas ao CoMÉRCIO DA OMC 192

Michelle Ratton Sanchez Badin e Marina Yoshimi Takitani

Os benefícios tributários do programa Inovar-Auto e os princípios da Nação Mais Favorecida e do Tratamento Nacional: uma análise dos argumentos dos Painéis atualmente em Curso contra o Brasil no Órgão de SoluÇão de Controvérsias da OMC . 211 Eric Moraes Castro e Silva

A ERA DA HUMANIDADE: REFLEXões PARA A HISTÓRIA DO DIREITO INTERNACIONAL 236 Henrique Weil Afonso

Precedentes vinculantes nos Estados Unidos da América e no direito brasileiro: Um ESTUDO COMPARADO 264

Patrícia Perrone Campos Mello 
IL DIRITTO AMBIENTALE SECONDO L'OTTICA DEL DIRITTO COSTITUZIONALE POSITIVO E LA RESPONSABILITÀ PER DANNI ALL'AMBIENTE NEL DIRITTO COMUNITARIO: LO STATO DELL'ARTE DEL DIRITTO AMBIENTALE COSTITUZIONALE E COMUNITARIO 287

Elcio Nacur Rezende

DA DESCONSIDERAÇÃo DA PERSONALIDADE JURÍDICA NAS RELAÇÕES CONSUMEIRISTAS BRASILEIRAS: ANÁLISE À LUZ DAS TEORIAS CLÁSSICAS

Daniel Amin Ferraz e Marcus Vinicius Silveira de Sá

ANALYSIS OF ADVANTAGES AND DISADVANTAGES OF FORUMS PRESCRIBED UNDER THE UNCLOS AND STATE PRACTICE: THE WAY AHEAD FOR INDIA ......................................................319

Vinai Kumar Singh

Do governo POR LEIS À governanÇA POR NúMERos: breve anÁlise do Trade in SERVICE AgreEMENT (TISA) ...............................................................................338 Jânia Maria Lopes Saldanha, Rafaela da Cruz Mello e Têmis Limberger

As DIRETIVAS EUROPEIAS COMO NORMA REGULADORA DO DIREITO ADMINISTRATIVO GLOBAL ..356 Alice Rocha da Silva e Ruth Maria Pereira dos Santos

O desenVolvimento da POlítica AGRícola COMUM dA UNião EUROPEIA 375 Tatiana de A. F. R. Cardoso Squeff

A imunidade de Jurisdição das organizaÇões internacionais FaCE AO Direito de aCESSO À JUSTIÇA 391

Fernanda Araújo Kallás e Caetano

O DIREITO INTERNACIONAL ENTRE O DEVER ÉTICO E A AÇÃo POLÍ́TICA: OS FUNDAMENTOS DE UM DEVER DE COOPERAÇÃO INTERNACIONAL NA FILOSOFIA POLÍTICA DE IMMANUEL KANT .405 Ademar Junior Pozzatti

EXTENSÃo E FRAGMENTAÇÃo NO CONTEXTO DA JURISDIÇÃO PENAL INTERNACIONAL .423 Marcus Vinícius Xavier de Oliveira

A DEFINiÇÃo JURÍdiCA DA "COMUNIDADE" .444 Nitish Monebhurrun, Michelle Lucas Cardoso Balbino, Fernanda Castelo Branco Araujo, Othon Pantoja, Míara Bogo Bruno e Cândida Dettenborn Nóbrega 
Comparative Study on Chinese Local Legislation of Science and Technology ProGRESS

LI Xiaoming e LI Yihan

O CONTROLE PENAL DO TRÁFICO DE PESSOAS: CONSTRUÇÃO JURÍDICA, INTERAÇÕES ORGANIZACIONAIS E COOPERAÇÃO INTERNACIONAL

Bruno Amaral Machado e Priscilla Brito Silva Vieira

Desativismo judicial: a extradição Battisti no Supremo Tribunal Federal .505 Francisco Rezek e Israel Paulino

A decisão norte-americana do Caso Myriad: novos paradigmas para a Proteção patenTÁRIA DO CÓDIGO GENÉTICO HUMANO E BIOTECNOLOGIA 514 José Carlos Vaz e Dias e Clarisse De La Cerda 


\section{Desafíos y respuestas transnacionales frente a los crímenes ambientales*}

\section{Challenges and Transnational Means to Tackle Environmental Crimes}

Rosmerlin Estupiñan-Silva**

\section{Resumen}

El desarrollo de herramientas represivas en materia ambiental hasta 2015 continúa marcado por el minimalismo y aunque las infracciones ambientales comparten la naturaleza transfronteriza de los crímenes internacionales, no siempre alcanzan el umbral de gravedad. Esto aunado a consideraciones económicas y de competencia territorial frena la eficacia normativa en la materia. Este trabajo busca poner en evidencia los medios de lucha contra la criminalidad ambiental en el mundo a través de un estudio comparado de los bienes jurídicos protegidos, la naturaleza del control estatal y el tipo de sanciones aplicadas. Una vez establecidas las características comunes de los medios de lucha en vigor, pondremos en evidencia la circulación de normas y prácticas transnacionales con base en criterios de eficacia y pertinencia. Como corolario sugerimos que la criminalización de las conductas más graves carece de efecto real en ausencia de políticas públicas estatales orientadas a la cooperación transnacional reforzada en materia de criminalidad ambiental.

Palavras-chave: crímenes ambientales, derecho transnacional, criminalización de condutas graves

\section{Abstract}

The development of repressive environmental tools until 2015 continues to be marked by minimalism, and although environmental violations share the cross-border nature of international crimes, they do not always reach the threshold of seriousness. This coupled with economic considerations and territorial competition slows down regulatory efficiency in this area. This paper seeks to highlight the means of combating environmental crime through a comparative study of protected legal rights, the nature of state control and the type of sanctions applied. Having established the common characteristics of the means of struggle in force, we will highlight the circulation of transnational rules and practices based on criteria of effectiveness and relevance. As a corollary, we suggest that the criminalization of the most serious conduct has no real effect in the absence of state public policies aimed at reinforced transnational cooperation in environmental crime.

Keywords: Environmental crimes, transnational law, criminalization of serious acts 


\section{INTRODUCCIÓN}

La lucha contra la criminalidad ambiental no sobrepasó la noción de diligencia debida (due diligence) ${ }^{1}$ hasta 1970, cuando Bolivia y Japón utilizaron por primera vez las sanciones penales para frenar el pillaje de los recursos naturales y la contaminación ${ }^{2}$. Esta intromisión del derecho penal en ámbitos usuales del derecho administrativo y ambiental fue consecuencia directa del aumento exponencial en la degradación del medio ambiente en el siglo XX, con riesgos ciertos para las generaciones futuras derivados de los excesos del antropocentrismo ${ }^{3}$ y de una política económica fundada en el beneficio financiero.

El siglo XXI ha sido escenario de toda una serie de factores novedosos concurrentes que resultan favorables a la respuesta punitiva en materia ambiental, entre otros: una comunidad internacional sensibilizada por las catástrofes ecológicas de origen humano ${ }^{4}$, una socie-

1 NÈGRE, C. Les atteintes massives à l'environnement. In: ASCENSIO, H.; DECAUX, E.; PELLET, A. Droit international penal. París: Pédone, 2000. p. 537. en particular, p. 538.

2 Decreto Supremo del Presidente de Bolivia, no 09328 de 23 de julio 1970, Reglamento relativo a delitos, infracciones y sanciones para quienes atenten contra los recursos naturales renovables; Dieta Japonesa, Act for Punishment of Pollution Endangering Human Health (Act No. 142 of 1970). ITOH, K. Japon: criminal protection o environment and the general part of criminal law in Japan. Revue Internationale de Droit Pénal, v. 65, n. 3/4, 1994. p. 1037. Disponible en: <http://www.derechoteca.com/gacetabolivia/decretosupremo-9328-del-23-julio-1970/>. Acceso: 20 jun. 2014.

3 DELMAS-MARTY, M. Préface. In: NEYRET, L. Des écocrimes à l'écocide: le droit pénal au secours de l'environnement. Bruselas: Bruylant, 2015. p. 8-13.

4 eg., las mareas negras de Torrey Canyon (Gran Bretaña, 1967), Amoco Cadiz (Francia, 1978), Exxon Valdez (Canadá, 1989), Erika (Francia, 1999), Prestige (España, 2002); los derrames tóxicos derivados de las explosiones de las fábricas en Flixborough (Gran Bretaña, 1974), Seveso (Italia, 1975), Toulouse (Francia, 2001), Jilin (China, 2005), Ajka (Hungría, 2010); al igual que los derrames tóxicos deliberados en Moulouya (Marruecos, 2011), e incluso las catástrofes nucleares de Tchernobyl (Ukrania, 1986) y Fukushima (Japón, 2011), sin hablar de otras catástrofes ecológicas previsibles derivadas de la deforestación de la Amazonía y la desertificación acelerada del continente africano, entre otros. dad civil $^{5}$ y una comunidad científica ${ }^{6}$ dinámicas y movilizadas por varias décadas, un conjunto de acuerdos encaminados a la adopción de medidas punitivas para enfrentar los atentados ambientales ${ }^{7}$ y la creación de numerosos órganos supranacionales en temas ambientales $^{8}$. La economía internacional en crisis se muestra

5 He aquí dos ejemplos recientes: la cartografía mundial de los conflictos ambientales que resulta del Proyecto EJOLT 20112015 (Environmental Justice Organisations, Liabilities and Trade), EJOLT, Environnemental Justice Atlas. Mapping ecological conflicts and space of resistance, 2014, disponible em: < http://ejatlas. org/>. Acceso: 13 jun. 2014; y la iniciativa ciudadana en Europa por la criminalización del Ecocidio: "Paremos el Ecocidio en Europa: una iniciativa ciudadana para dar derechos a la tierra", doc. ECI(2013)00000, Draft Directive européenne sur l'Ecocide, 2013, disponible en: <http://ec.europa.eu/citizensinitiative/public/initiatives/ongoing/details/2013/000002>. Acceso: 17 jun. 2014.

6 En 1992, la Asociación Internacional de Derecho Penal (AIDP) movilizó más de veinticinco Estados, además de delegaciones de Naciones Unidas, del Consejo de Europa, académicos y litigantes, para analizar el alcance del derecho frente a los atentados ambientales. En 2014, el Grupo Intergubernamental de Expertos sobre Cambios Climáticos (GICC, GIEC en francés y IPCC en inglés, creado en 1988) presentó su quinto Informe con un resumen dirigido a los responsables políticos, que contiene una serie de recomendaciones para hacer frente a los desafíos climáticos. En 2015 , con los auspicios de la Misión Derecho y Justicia de Francia, un grupo de expertos produjo una obra colectiva que además de un análisis académico exhaustivo contiene dos propuestas de tratados sobre la criminalidad ambiental y el ecocidio. v. AIDP, XVème Congrès international de droit penal. Rio de Janeiro, 4-10 septembre 1994, Section I: Infractions contre l'environnement. Application du droit pénal général, Revue Internationale de Droit Pénal, v. 66, n. 1-2, 1995, p. 22 ; IPCC, Climate Change 2014. Mitigation of Climate Change. Summary for policy-makers, PIK, Postdam, 2014; NEYRET, L. Des écocrimes à l'écocide: le droit pénal au secours de l'environnement. Bruselas: Bruylant, 2015. 465 p.

7 Pueden evocarse, sin pretenciones de exhaustividad, entre los acuerdos adoptados que preveen la creación de sanciones penales en el derecho penal interno para toda infracción ambiental grave: El Convenio de Londres sobre la prevención de la contaminación del mar por vertimientos de desechos y otras materias, (1972), la Convención de las Naciones Unidas sobre el Derecho del Mar (1982), y el Convenio de Basilea sobre el control de los movimientos transfronterizos de los desechos peligrosos y su eliminación (1989). Podemos hacer alusión igualmente a otros instrumentos jurídicos internacionales como la resolución de Naciones Unidas 45/107 de 1990 y su Anexo de Recomendaciones sobre la cooperación Internacionesl para la prevención del delito y la justicia penal en el contexto del desarrollo. En el mismo sentido, la Resolución 77(28)/1990 del Consejo de Europa (Contribución del Derecho Penal en la protección del Medio Ambiente) insta a los Estados miembros a (rendre criminelle l'atteinte à l'environnement de sorte que l'auteur de l'infraction risque d'être poursuivi non seulement dans le pays où l'acte a été commis mais aussi dans tous les autres pays qui en subissent les conséquences, sous réserve $d u$ principe de l'autorité de la chose jugée) y la Directiva 2008/99/CE del Parlamento Europeo y del Consejo de 19 noviembre 2008, relativa a la protección del medio ambiente mediante el Derecho penal refuerza la obligación estatal a los mismos efectos.

8 Además del GICC, pueden mencionarse, por ejemplo: el Pro- 
más atenta al carácter limitado de los servicios ambientales ${ }^{9}$ y (por lo menos en apariencia) más dispuesta a aceptar la implementación de una reglamentación sobre el uso de los recursos naturales y el control de las actividades ilícitas derivadas ${ }^{10}$. En el siglo XXI los atentados contra el medio ambiente son por primera vez estudiados bajo un ángulo diferente: se trata de un problema planetario cuya solución solo puede ser concebida a escala internacional y requiere la participación activa de los Estados.

No obstante esta declaración de intenciones vivamente expresada en el nivel internacional, la redacción de disposiciones nacionales pertinentes en la materia se mantiene vaga, debilitando de contera las fases de sanción y ejecución de sentencias. La impresición de los términos utilizados en la lucha contra la criminalidad ambiental puede ser imputada a una serie de factores concurrentes: el entrecruzamiento de disciplinas del derecho diferentes en cuanto a medios y principios, la ausencia de acuerdo acerca del titular de los derechos protegidos ${ }^{11}$ y la preponderancia de intereses económicos de escala global sobre otros derivados de la protección del entorno natural.

grama de Naciones Unidas para el Medio Ambiente (PNUMA), el Earth System Governance Project et le World Nature Organization (WNO); el Partnerships in Environmental Management for the Seas of East Asia (PEMSEA), la Agencia Europea de Medio Ambiente (AEMA, AEE en francés), y el Programa de Derecho Ambiental, politicas y gobernabilidad del Departamento de Desarrollo Sostenible de la Organización de Estados Americanos (OEA).

9 "Funciones ambientales" o "servicios ambientales" (environmental services) es un concepto de economía ecológica que se refieren a "cualquier atributo funcional de los ecosistemas naturales que sea manifiestamente benéfico para la humanidad". Creemos que este término tiene su utilidad para ilustrar nuestros prostulados a lo largo de este capítulo que, en la práctica, trata de explicar las herramientas actuales para el control transnacional sobre la economía en materia de medio ambiente. UNITED NATIONS. Glossary of Environment Statistics: studies in methods. New York, 1997. (Series F, n. 67). Available: <https://stats.oecd.org/glossary/detail.asp?ID=843> . Access: 17 jan. 2014.

10 BANCO MUNDIAL. Global partnership for wealth accounting and the valuation of ecosystem services (WAVES). Washington DC, 2011. Available: <www.wavespartnership.org/waves>. Access: 17 jan. 2014. EU, doc. COM 147 (1st April 2009): White paper: Adapting to climate change: towards a European framework for action, en particular, p. 16 ; DALY, H. from a failed growth economy to a steadystate economy in the road to Rio+20. New York: CNUCED, 2011. p. 11. Available: <www.uncsd2012.org/rio20/index.php?page=view\&typ $\mathrm{e}=400 \& \mathrm{nr}=11 \& \mathrm{menu}=45>$. Access: 17 jan. 2014.

11 Una buena parte de la doctrina considera que el medio ambiente no puede ser titular de derechos y solo en épocas recientes se habla de los deberes de cuidado de la humanidad frente a su entorno natural., v. DELMAS-MARTY, M. Préface. In: NEYRET, L. Des écocrimes à l'écocide: le droit pénal au secours de l'environnement. Bruselas: Bruylant, 2015. p. 7.
En consecuencia, la respuesta estatal se ve confrontada a dos debilidades mayores: la inadecuación de las fuentes de derecho aplicable, derivada de su dispersión, pertinencia, accesibilidad, adaptabilidad y eficacia; y, la ausencia de un procedimiento unificado para el tratamiento de las infracciones, lo que genera paraísos ambientales de impunidad por incompetencia ratione personae, ratione materiae, ratione temporis y ratione loci. Cuarenta y tres años después de la Declaración de Estocolmo de 1972, el derecho nacional aún se debate entre la consolidación de medios de lucha (I) de naturaleza constitucional, administrativa o penal, y una implementación de dichas herramientas surcada por factores que limitan su eficacia y claman por respuestas transnacionales (II).

\section{LA CONSOLIDACIÓN DE LOS MEDIOS DE LUCHA ESTATALES}

La protección de elementos ambientales específicos es de tradición milenaria. La presencia de una fuente internacional de derecho derivada de la práctica consuetudinaria de los Estados en materia ambiental ha sido evocada por una parte de la doctrina ${ }^{12}$ y podemos coincidir acerca de la existencia de una prohibición de causar graves atentados ambientales que tiene por vocación devenir norma de ius cogens. No obstante, es preciso aclarar que los primeros límites impuestos a la destrucción del entorno natural, consignados en el Antiguo Testamento, en los escritos de Sun Tzu o en la obra de Cicerón, estuvieron ligados a la protección militar estratégica del ejército ocupante y a los intereses estratégicos de los gobernantes ${ }^{13} \mathrm{y}$ en ningún caso al medio ambiente, la seguridad del planeta o la salud humana como valores protegidos. Por razones siempre estratégicas y en algunos casos culturales, China, por ejemplo, tiene una tradición milenaria en la protección de los suelos y las aguas y Finlandia ha hecho lo propio con las corrientes de agua dulce ${ }^{14}$. La protección de aguas y bosques fue

12 HELLIO, H. Vers un droit pénal commun de l'environnement: critères et techniques d'incriminnation. In: NEYRET, L. Des écocrimes à l'écocide: le droit pénal au secours de l'environnement. Bruselas: Bruylant, 2015. p. 109-126. en particular p. 116-121.

13 ESTUPIÑAN SILVA, R. Orígenes remotos de las leyes y usos de la guerra. Derecho Internacional y crímenes de guerra en Colombia, Bogotá, p. 3-8, 2013.

14 PRABHU, M. Rapport general: Les atteintes à l'environnement : problèmes de droit pénal general. Revue Internationale de Droit Pénal, v. 65 , n. 3-4, 1994. p. 663. en particular, p. 671 ; NUOTIO, K. Rap- 
usada por Francia desde el siglo XVII como medio para proteger el patrimonio y la seguridad nacional $(1669)^{15}$ y en Chile desde el siglo XIX con el mismo objetivo $(1872)^{16}$. El medio ambiente empezó a ser objeto de una protección indirecta, mediada por la protección de actividades lucrativas como la pesca, el turismo y la industria en Bélgica desde el siglo XVIII $(1789,1888)^{17}$. La protección indirecta del entorno natural también fue usada como medio para la protección de la salud humana a partir del siglo XIX en Egipto $(1877)^{18}$ y en Estados Unidos de América (1889) ${ }^{19}$.

Los medios de protección ambiental son instaurados a menudo a partir de consideraciones estratégicas estatales que devienen principios constitucionales (A), normas administrativas (B) e incluso infracciones penales (C), y que serán implementados a través de instituciones estatales de distinta índole. En efecto, la naturaleza de los medios y autoridades responsables demuestra ampliamente el interés estatal y los intereses en juego en la materia.

\subsection{Protección constitucional}

La protección general del medio ambiente por vía constitucional es una herramienta jurídica que data de

ports nationaux: Finlande. Revue Internationale de Droit Pénal, v. 65, n. 3-4, 1994. p. 923.

15 Decreto Real de Luis XIV de agosto 1669 y Decreto de agosto de 1681 sobre las aguas territoriales para la protección de puertos y costas. ROBERT, J. H. France: le problème de la responsabilité et des sanctions pénales en matière d'environnement. Revue Internationale de Droit Pénal, v. 65, n. 3-4, 1994. p. 947. en particular, p. 951.

16 Leyes de la llamada "corta de bosques" y Decreto de 16 enero 1879 relativo a las "reservas de bosques fiscales" de Chile.

17 Decretos de 1789, Código Forestal de 1854, Código Penal de 1867, Código Rural de 1886, Leyes de protección de la "beauté des sites" (belleza de los lugares), Decreto Ley de 5 mayo 1888 sobre la inspección de los establecimientos que presenten ambientes malsanos y peligrosos. HENNAU-HUBLET, C.; PIRET BELGIQUE, J. M. Les crimes contre l'environnement en droit belge. Revue Internationale de Droit Pénal, v. 65, n. 3-4, 1994. p. 777. en particular, p. 777-778.

18 Reglamentos de 1877 y 1893 relativos a la localización de los cementerios y mataderos municipales en relación con los ríos y los canales, entre otros. FATHY SOROUR, A. Egypte I: La protection de l'environnement en droit pénal égyptien. Revue Internationale de Droit Pénal, v. 65, n. 3-4, 1994. p. 865. en particular, p. 866.

19 KELLMAN, B., United States: Criminal Law and Evironmental Protection. Revue Internationale de Droit Pénal, v. 65, n. 3-4, 1994. p. 885 . en particular, p. 885 . Paradójicamente, Davis señala la existencia, en el seno de Estados Unidos, de territorios "superfluos" en materia ambiental como la gran cuenca del Este californiano, entre otros. DAVIS, M. The Dead West: ecocide in marlboro country. New Left Review I/200, 1993. en particular, p. 7. mediados del siglo XX. La protección ambiental como elemento autónomo y patrimonio de la humanidad es, hasta 2015, un signo distintivo excepcional de tres constituciones suramericanas: Ecuador, Bolivia y Bra$\operatorname{sil}^{20}$. No obstante, numerosas constituciones modernas contienen normas específicas relativas a la protección ambiental a la vez como deber del Estado, como deber ciudadano y como derecho humano, individual o colectivo, compatible con otros derechos como la propiedad o el ejercicio del comercio y de las profesiones.

En 1989, Carmona ${ }^{21}$ señaló la marca ambiental en las Constituciones de Chile, El Salvador, Guatemala, Panamá, Nicaragua y México. En 1994, Prabhu ${ }^{22}$ incluyó Austria, Brasil, China, España, Grecia, Países Bajos, Perú, Polonia, Portugal, Rumania, Suiza y Turquía, así como algunas constituciones estatales dentro de los Estados Unidos de América (Massachusetts, Carolina del Norte, Pennsylvania).

En 2013, durante nuestro estudio comparado de cincuenta y dos Estados ${ }^{23}$, cuarenta de ellos se refieren a un medio ambiente sano como un derecho humano y / o como deber del Estado, a saber: Australia, Bielorrusia, Bolivia, Brasil, Bulgaria, Chile, China, Colombia, Corea del Sur, Costa Rica, Croacia, Cuba, El Salvador, Ecuador, Eslovenia, Guatemala, Guyana, Haití, Honduras, India, Indonesia, Jamaica, Kosovo, Macedonia, México, Montenegro, Nicaragua, Panamá, Paraguay, Perú, Polonia, República Dominicana, República Eslovaca, Rusia, Serbia, Sudáfrica, Surinam, Ucrania, Uruguay y Venezuela.

En el seno de la Unión Europea, todos los 27 Estados miembros incluyen elementos ambientales en sus

20 Artículo 33 de la Constitución de Bolivia (2009), artículo 395 de la Constitución del Ecuador (2008) y artículo 225 de la Constitución de Brasil (reformada en 1996).

21 CARMONA LARA, M. C. Análisis de la legislación ambiental de América Latina. Boletín Mexicano de Derecho Comparado, n. 64, 1989. p. 15 , en particular, p. 22-24.

22 PRABHU, M. Rapport general: les atteintes à l'environnement: problèmes de droit pénal general. Revue Internationale de Droit Pénal, v. 65, n. 3-4, 1994. p. 676.

23 ESTUPINANAN-SILVA, R. (Coord.) Report on the Ecocide Project. Paris: Sciences Po Law Clinic, 2013. p. 36-66. p. 153. Disponible en: <http://www.sciencespo.fr/ecole-de-droit/sites/sciencespo. fr.ecole-de-droit/files/rapport_ecocide_project.pdf $>$. Acceso: 05 jun. 2015. Los doce países bajo estudio que no mencionan el medio ambiente en su Constitución son: Bahamas, Barbados, Belice, Bosnia y Herzegovina, Canadá, Estados Unidos de América, Japón, República Checa, Reino Unido, San Vicente, Santa Lucía, Trinidad y Tobago. 
constituciones respectivas con mayor o menor énfasis, en el marco de sus compromisos convencionales. Francia en 2005, por ejemplo, anexó una Carta del Medio Ambiente al preámbulo de su Constitución, como parte su bloque de constitucionalidad, reconociendo derechos humanos y deberes fundamentales de protección ambiental en materia de prevención, precaución y del principio de quien contamina paga. El derecho a un ambiente decente o sano ha sido igualmente abordado como un componente de otros derechos humanos por vía jurisprudencia estatal a través del derecho a la salud en Argentina ${ }^{24}$, a través del derecho a la vida en Alemania ${ }^{25}$ y en la India ${ }^{26}$, esta última llegando incluso a aceptar el actio popularis (public interest litigation : PIL), entre otros.

En el plano internacional de los derechos humanos, a lo largo de las últimas décadas el medio ambiente ha sido evocado como medio para la protección de derechos fundamentales a la vida, la vida privada y familiar, la salud, la propiedad, la identidad cultural, entre otros. Podemos en este punto citar casos célebres de la Corte Europea de Derechos Humanos como López Ostra vs. España (1994), Fadeyeva vs. Rusia (2005) y Giacomelli vs. Italia (2006) donde el medio ambiente sano se estudió bajo el ángulo del artículo 8 del Convenio Europeo de Derechos Humanos (vida privada y familiar). En el marco regional africano, la Comisión Africana de Derechos Humanos y de los Pueblos en su comunicación del caso Social and Economic Social Rights Centre vs. Nigeria (2001) estableció una responsabilidad estatal directa en casos de degradación ambiental causada por un actor privado, basándose entre otros, en el artículo 24 (derecho de los pueblos a un ambiente satisfactorio) de la Carta Africana y en el derecho a la salud. Por su parte, la Corte Interamericana de Derechos Humanos en el caso Káwas Fernández vs. Honduras (2009) abordó la violación del artículo 4 de la Convención Americana de Derechos Humanos (derecho a la vida), como con-

24 Corte Suprema Federal de Argentina, 8 de julio de 2008: Mendoza, Beatriz Silvia et al. vs. Estado Nacional et al, s/ indemnizaciones (derivadas de la contaminación del río Matanza - Riachuelo), expediente M. 1569. XL, Sentencia.

25 HEINE, G. Allemagne. Crimes against the environment. Revue Internationale de Droit Pénal, Revue Internationale de Droit Pénal, v. 65, n. 3-4, 1994. p. 731, en particular, p. 737 y nota 25.

26 Corte Suprema de India, Vellore Citizens' Welfare Forum vs. Union of India, Sentencia de 28 de agosto de 1996, AIR 1996 SC 2716; SAHU, G. Implications of Indian Supreme Court's Innovations for Environmental Juriprudence Law. Environment and Development Journal, v.1/4, 2008. p. 3. secuencia del ejercicio ciudadano de la protección ambiental, en un extenso análisis relativo a los defensores y activistas del medio ambiente ${ }^{27}$. Los enfoques podrán ser individuales o colectivos en el abordaje de los derechos, pero retendremos que los tribunales constitucionales al igual que los tribunales regionales de derechos humanos no se hallan facultados para proteger el medio ambiente como derecho fundamental en sí, sino como medio para la protección de derechos y libertades individuales, en el marco de las obligaciones positivas de los Estados (deber de proteger). En la misma línea de análisis, las medidas cautelares y de reparación conciernen el entorno natural únicamente en la medida en que es indispensable para el desarrollo de una comunidad en un contexto dado y esto se refiere particularmente a las comunidades indígenas y tribales, en particular en el sistema interamericano desde la sentencia de Mayagna vs. Nicaragua (2001), donde el vínculo intrínseco de las comunidades tradicionales y sus miembros frente a sus territorios tradicionales fue admitido como componente inherente del derecho a la vida (artículo 4). Esta jurisprudencia fue consolidada en la sentencia de Saramaka vs. Surinam (2007) y compilada en Sarayaku vs. Ecuador $(2012)^{28}$.

Más allá de los principios constitucionales, los atentados contra el medio ambiente son a menudo objeto del derecho administrativo debido a sus efectos sobre la economía y la seguridad pública (B). Solo en la medida en que la integridad del medio ambiente trasciende la idea de utilidad para devenir un valor jurídico reconocido y protegido por el Estado, el lugar del derecho penal

27 Para un estudio más detallado del enfoque ambiental de la jurisprudencia de derechos humanos $v$, por ejemplo, MARTIN-CHENUT, K.; PERUSSO, C. La contribution des systèmes régionaux de protection des droits de l'homme à la pénalisation des atteintes à l'environnement, In: NEYRET, L. Des écocrimes à l'écocide: le droit pénal au secours de l'environnement. Bruselas: Bruylant, 2015. p. 39-65; ESTUPIÑAN-SILVA, R.; EL, Quesada B. Proceso HaberBosch en la sociedad agroindustrial: peligros y alternativas. Revista El Otro Derecho, n. 42, 2011. p. 75. en particular, p. 83 y ss.

28 ESTUPIÑAN SILVA, R. Pueblos indígenas y tribales: la construcción de contenidos culturales inherentes en la jurisprudencia interamericana de derechos humanos. Anuario Mexicano de Derecho Internacional AMDI, v. 14, p. 581-616, 2014.; ESTUPIÑAN SILVA, R.; IBAÑEZ RIVAS, J. La jurisprudencia de la Corte Interamericana de Derechos Humanos en materia de pueblos indígenas y tribales. In: BELTRAO, J. F. et al. Derechos bumanos de los grupos vulnerables. Barcelona: Edo-Serveis, 2014. p. 301-336; MARTIN-CHENUT, K.; PERUSSO, C. La contribution des systèmes régionaux de protection des droits de l'homme à la pénalisation des atteintes à l'environnement, In: NEYRET, L. Des écocrimes à l'écocide: le droit pénal au secours de l'environnement. Bruselas: Bruylant, 2015. p. 39-65. 
como herramienta de protección retoma su importancia (C).

\subsection{Respuesta administrativa}

Luego de su estudio de veinticinco países en $1994^{29}$, la Asociación Internacional de Derecho Penal publicó su diagnóstico, asociando los daños ambientales a tres tipos de conductas que conservan aún toda su actualidad: el no respeto de la reglamentación, la negligencia grave en el ejercicio de una actividad industrial y el hecho deliberado de las industrias. Frente al no respeto y la negligencia grave, las respuestas jurídicas recomendadas en 1994 fueron de naturaleza administrativa. Solo en caso de hecho deliberado de las industrias se evocó la relevancia probable para el derecho internacional penal, cuando un cierto umbral de gravedad es alcanzado ${ }^{30}$. En nuestro estudio de 2013 puede constarse un fortalecimiento neto de las medidas administrativas en casos de no respeto de la reglamentación ambiental y las sanciones penales han sido implementadas no solo en casos de falta intencional sino el algunos casos de negligencia grave $^{31}$. En Sudáfrica por ejemplo, los hechos materia de reglamentación ambiental son agrupados en cinco temáticas: vertimiento de desechos, contaminación del aire, construcción sin autorización, atentados contra especies protegidas y la minería no autorizada. Estas temáticas pueden variar según los contextos e intereses de los Estados pero, por regla general, se mantienen estables. Estados Unidos de América, por ejemplo, dedica además una especial atención a la contaminación marina y de las aguas. Otros Estados con grandes reservas de biodiversidad como China o países latinoamericanos como Guatemala, Nicaragua, México, Panamá, Colombia o Brasil, protegen en particular los bosques, la flora y la fauna salvajes ${ }^{32}$.

29 En su orden de aparición: Austria, Bélgica, Brasil, Canadá, China, Egipto, España, Estados Unidos de América, Finlandia, Francia, Grecia, Hungría, Israel, Italia, Japón, Luxemburgo, Países Bajos, Perú, Polonia , Portugal, Rumania, Suecia, Suiza.

30 FITZGERALD, P. Commentaire et questions préparatoires. Revue Internationale de Droit Pénal, v. 65, n. 3-4, 1994. p. 643. en particular, p. 644.

31 Además de la Directiva 2008/99/CE obligatoria para los veintisiete Estados de la Unión Europea. ESTUPIÑAN-SILVA, R. (Coord.). Report on the Ecocide Project. Paris: Sciences Po Law Clinic, 2013. p. 66 y ss.

32 La reglamentación pertinente de los países mencionados puede consultarse en francés o inglés en: ESTUPIÑAN-SILVA, R. (Coord.). Report on the Ecocide Project. Paris: Sciences Po Law Clinic, 2013. p. 66-81.
En todos loso casos, el rol del derecho administrativo en materia ambiental es determinante. Además de los procedimientos de no cumplimiento normativo que se rigen completamente por el derecho administrativo, es común que las infracciones penales ambientales requieran ser completadas por una definición exterior de naturaleza administrativa, es decir, se trata de infracciones usualmente conocidas como tipos penales en blanco (blanket criminalization) ${ }^{33}$.

En materia de jurisdicción, la gama de autoridades competentes varía según la estructura del Estado y de su pertenencia a órganos internacionales. En Estados con centralización política la reglamentación administrativa depende del poder ejecutivo, en el marco de leyes estatutarias emanadas del parlamento. La variante más importante de esta regla general se observa en países con divisiones administrativas autonómicas o federales importantes. Estados federales como Alemania, Brasil, Canadá, Estados Unidos de América, México o Venezuela, cuentan con leyes ambientales que sirven únicamente como marco, pues la reglamentación y la sanción dependen en buena medida de las autoridades locales y estaduales. En países confederados como Suiza o con fuertes autonomías propias del Estado región como Bélgica España o Italia, la independencia normativa es mucho más importante y variada.

Las autoridades administrativas imponen por regla general sanciones pecuniarias en caso de atentados ambientales $^{34} \mathrm{y}$ el individuo infractor de la norma administrativa solo es objeto de privación de la libertad cuando

33 ESTUPIÑAN-SILVA, R. (Coord.). Report on the Ecocide Project. Paris: Sciences Po Law Clinic, 2013. Este aspecto ha sido materia reciente de nuevas críticas en el marco de la implementación de la Directiva Europea 2008/99/CE. v. Cour de Cassation de Belgique, Rapport de M. GOETHALS, Etienne. Sur le droit pénal de l'environnement. In: ACTES de la Réunion constitutive du comité sur l'environnement de l'Association des cours judiciaires suprêmes francophones AHJUCAF. Porto-Novo, 2008. p. 41 ; FAURE, M. Responsabilité pénale environnementale en Europe: quo vadis? In: FONDEMENTS et objectifs des incriminations et des peines en droit européen et en droit international. Anthémis, 2013. p. 331, SADELEER, N. Responsabilité pénale environnementale. Examen des relations douteuses entre le droit international, le droit de l'UE, et le droit pénal national. In: FONDEMENTS et objectifs des incriminations et des peines en droit européen et en droit international. Anthémis, 2013. p. 307.

34 Sobre este punto vale la pena mencionar, por ejemplo, la crítica sobre la implementación insuficiente de sanciones pecuniarias en el seno de los países de common law. v. OGUS, A.; ABBOT, C. Sanctions for Pollution: do we have the right regime? Journal of Environnemental Law, v. 14, 2002, p. 283. 
rehúsa el pago ${ }^{35}$. Las sanciones administrativas dirigidas contra la persona jurídica son de naturaleza y de severidad diversas: puede tratarse del cierre de la empresa, la suspensión o renovación de permisos, el embargo, la confiscación de las ganancias patrimoniales, o incluso la reparación de daños causados, la restitución, la orden de restauración o rehabilitación, los trabajos de interés general, entre otros ${ }^{36}$.

A la hora actual, el derecho punitivo ambiental reviste una naturaleza pluridimensional y retendremos que, en general, existe una diferencia neta entre las infracciones penales y las infracciones administrativas, estas últimas mayoritarias y enmarcadas en leyes y decretos específicos ${ }^{37}$.

No obstante, a medida que avanza el siglo XXI, el derecho administrativo parece acercarse al derecho penal en cuanto a la severidad de los medios empleados para combatir los atentados ambientales. En 2001, por ejemplo, el Parlamento italiano creó la infracción administrativa llamada "actividad organizada de comercio ilegal de desechos" (artículo 53 bis, DLGS 22/97, transformado en el artículo 260, DLGS 152/2006), que permite utilizar las herramientas propias a una investigación criminal (eg., escuchas telefónicas, vigilancia electrónica), arrestar personas sospechosas de tráfico de desechos, impulsar mandatos internacionales de persecución y aplicar tiempos de prescripción mayores que para otras infracciones ambientales. Esta infracción, pese a su naturaleza administrativa podría ser considerada como una verdadera infracción penal o en todo caso cuasi-penal por la severidad de los medios adoptados.

Así pues, el ingreso del derecho penal en el ámbito

35 PRABHU, M. Rapport general: les atteintes à l'environnement: problèmes de droit pénal general. Revue Internationale de Droit Pénal, v. 65, n. 3-4, 1994. en particular, p. 689.

36 PRABHU, M. Rapport general: les atteintes à l'environnement : problèmes de droit pénal general. Revue Internationale de Droit Pénal, v. 65 , n. 3-4, 1994. en particular, p. 674; ESTUPIÑAN-SILVA, R. (Coord.). Report on the Ecocide Project. Paris: Sciences Po Law Clinic, 2013. p. 66 y ss.

37 BITTO, M.; FÜLÖP, S. Hongrie. Crimes against the environment. Revue Internationale de Droit Pénal. v. 65, n. 3-4, 1994, p. 973. En cuanto a los pioneros de la distinción citada: Alemania y Japón, HEINE, G. Germany. Crimes against the environment. Revue Internationale de Droit Pénal, v. 65, n. 3-4, 1994. p. 731; ITOH, K. Japon: criminal protection o environment and the general part of criminal law in Japan. Revue Internationale de Droit Pénal, v. 65, n. 3/4, 1994. en particular, p. 1040. Finalmente, he aquí dos ejemplos de leyes específicas: los Decretos no 2005-935 de 2 de agosto de 2005 y n n $^{\circ} 2007$ 397 de 22 de marzo de 2007 relativos al Código del Medio Ambiente en Francia y la Mining Act de 1995 en Filipinas. ambiental es una consecuencia de la poca eficacia del derecho administrativo ambiental ${ }^{38}$, evaluada por algunos autores como un reflejo de los egoísmos estatales ${ }^{39}$, e introduce discusiones relativas a la autonomía de los tipos penales con respecto a las normas administrativas: ¿derecho penal autónomo o accesorio? Esta discusión entraña un dilema sobre la función predominante del derecho privado por oposición al derecho público en materia de criminalidad ambiental, que puede tener interés en sistemas jurídicos que suelen integrar el derecho penal al derecho privado como Francia, pero carece de contenido en la mayor parte de los sistemas jurídicos del mundo de civil law y de common law, donde el derecho penal sigue formando parte del derecho público.

\subsection{Jurisdicción penal}

Toda infracción penal es un hecho imputable dotado de un elemento material y un elemento intencional. Para efectos prácticos, haremos uso de los elementos de los crímenes descritos en el artículo 30 del Estatuto de Roma de 1998 que dio nacimiento a la Corte Penal Internacional y de su Anexo B sobre "los elementos de los crímenes". En consecuencia, vamos a estudiar tres elementos materiales: de comportamiento, de consecuencia y de circunstancia, al igual que los elementos psicológicos o intencionales (mens rea) y a las circunstancias de contexto que constituyen el factor determinante de la potencialidad internacional de un crimen en función de su gravedad.

Los crímenes ambientales abordan por lo menos cuatro temáticas (ratione materiae) bien precisas: las actividades peligrosas (contaminación de las aguas, el aire, el suelo, eliminación de residuos industriales), la biodiversidad (destrucción de especies, agotamiento de recursos), la bioseguridad (comercio ilícito, patrimonio genético, plagas) y la gestión ambiental de los recursos naturales. Los atentados contra el medio ambiente son a menudo clasificados como contravenciones, delitos y crímenes (los más graves). Sin embargo en sistemas an-

38 Esto queda constatado por el considerando 3 de la Directiva Europea 2008/99/CE que impone a los veintisiete Estados miembros de la Unión Europea la obligación de sancionar penalmente ciertos comportamientos que constituyan atentados graves contra el medio ambiente.

39 BEAUVAIS, P. Les limites de l'internationalisation du droit pénal de l'environnement. In: NEYRET, L. Des écocrimes à l'écocide: le droit pénal au secours de l'environnement. París: Bruylant, 2015. p. 3-18, en particular p. 5. 
glófonos y francófonos, la noción de delito se subsume en la noción de crimen. En todo caso, al igual que el derecho administrativo, las materias de competencia se mantienen uniformes y solo varían según intereses específicos derivados de los recursos naturales protegidos por el Estado en cuestión.

El medio ambiente aparece en derecho penal primero como medio para proteger la seguridad del Estado y, en su evolución, otros bienes jurídicos (valores) protegidos $^{40}$ por los tipos penales ambientales generalmente conciernen los derechos de los individuos a la vida, la integridad (incluida la salud) y la propiedad. En las últimas décadas, y como excepción, algunos crímenes ambientales aparecen asociados al medio ambiente como bien jurídico autónomo. Situar los crímenes en la jerarquía de valores (bienes jurídicos) reconocidos por el Estado es fundamental para poder aplicar correctamente las normas. El reconocimiento del bien jurídico protegido no siempre es evidente porque los crímenes ambientales son de naturaleza plural. Cuando el legislados protege la seguridad pública, los crímenes ambientales más graves (crímenes stricto sensu) pueden encontrarse en el mismo nivel que otros crímenes graves como los actos de terrorismo, por ejemplo. Si el legislador busca proteger la vida humana, dichos crímenes se hallan situados junto a los atentados graves contra la vida. En esta línea de ideas, cuando el legislador entiende proteger el medio ambiente en sí mismo, los crímenes ambientales tienen un lugar autónomo en la ley penal. Sin embargo, asuntos como la intencionalidad, el sujeto imputable y los elementos extrajurídicos del tipo son temas a precisar dentro de la ley en un ánimo de coherencia y eficacia.

La primera noción a retener es que los elementos materiales de los crímenes ambientales pueden ser actos u omisiones, según la fórmula empleada por cada legislador ${ }^{41}$. En cuanto al tipo de conducta, la exigencia de un elemento material de resultado es una excepción en materia de infracciones ambientales. No es común que

$40 \quad$ El criterio de clasificación penal inspirado en la protección de bienes jurídicos (valores jurídicos) es utilizado en este estudio como un concepto común al derecho penal de los sistemas jurídicos de tradición civilista (romano germánica) y del common law. Retendremos en especial entre los valores protegidos, la primera distinción fundamental que opone los intereses públicos (del Estado y de la sociedad) a los intereses privados (de los individuos).

41 Las omisiones forman parte de los comportamientos sancionados por los crimenes ambientales, como también han formado parte histórica del derecho penal de los Estados. La Directiva Europea 2008/99/CE se refiere a ellas en el considerando 6 como "incumplimiento de una obligación a bacer?. el perjuicio sea un elemento requerido por la infracción, pues los crímenes ambientales hacen énfasis en la eficacia preventiva de la norma. En la mayoría de los sistemas penales es suficiente con probar el elemento material de comportamiento y la circunstancia, es decir el hecho que dicho comportamiento tiene vocación de poner en peligro el bien jurídico protegido ${ }^{42}$. La obligatoriedad de un resultado y más aún, la exigencia concurrente de causalidad y de resultado (el nexo), donde han sido implementadas han tenido como resultado destruir la función de la infracción ${ }^{43}$. En este sentido, aunque la doctrina se ha preguntado si los tipos penales ambientales de peligro pueden infringir los límites del principio nullum crime sine injuria, la jurisprudencia estatal ha retenido como elementos de juicio, caso por caso, los principios sana crítica del juez y de equilibrio de derechos entre la víctima y el acusado ${ }^{44}$.

En materia de elemento intencional (mens rea), el conocimiento y la intención son los componentes requeridos en derecho penal como regla general, también para las infracciones ambientales. Dicho esto, en materia ambiental la intención se asocia igualmente a la negligencia grave en los veintisiete países de la Unión Europea y en países como Canadá, Israel, Brasil, Colombia y México, entre otros ${ }^{45}$. Por el contrario, cuando concurre

42 La Directiva Europea 2008/99/CE aborda este punto en su artículo 3, relativo a las infracciones que "causen o sean susceptibles de causar" el daño esperado; el artículo 347-A del Código Penal de Guatemala, por ejemplo, prohibe la contaminación, entre otros, a través del "abandono de productos que puedan causar un perjuicio"; el artículo 54 de la Ley brasilera $n^{\circ} 9.605$ de 12 de febrero de 1998 ordena una serie de sanciones penales y administrativas derivadas, entre otras, de la contaminación que alcance un nivel tal que "cause o pueda causar" perjuicios a la salud humana, animal o a la flora.

43 Este fue el caso de Austria y de Suecia hasta 1994, pues los dos sistemas exigían probar el comportamiento, el resultado y el nexo de causalidad entre ellos. FUCHS, H. Autriche. Crimes against the environment. Problems of the general part. Revue Internationale de Droit Pénal, v. 65, n. 3-4, 1994. p. 761, en particular, p. 764 ; STEEN-SUNDBERG, C. Suède. Crimes against the environment in Sweden. Revue Internationale de Droit Pénal, v. 65, n. 3-4, 1994. p. 1163 y s.; Sobre la importancia de los tipos penales de peligro, véase igualmente: D'AMBROSSIO, L. Vers un droit pénal commun de l'environnement: critères et techniques d'incriminnation. In: NEYRET, L. Des écocrimes à l'écocide: le droit pénal au secours de l'environnement. Bruselas: Bruylant, 2015. p. 87-107, en particular p. 100.

44 CARACCIOLI, I. Italie. La protection de l'environnement en droit pénal italien. Revue Internationale de Droit Pénal, v. 65, n. 3-4, 1994. p. 1013; ESTUPIÑAN-SILVA, R.; El, Quesada B. El proceso Haber-Bosch en la sociedad agroindustrial: peligros y alternativas. Revista El Otro Derecho, n. 42, 2011. en particular, p. 85.

45 PRABHU, M. Rapport général. Les atteintes à l'environnement: problèmes de droit pénal general. Revue Internationale de Droit Pénal, 
la ausencia de intención y la ausencia de obligación de cuidado especial, la respuesta no es penal sino administrativa en los 42 Estados estudiados ${ }^{46}$ y en los 27 Estados miembros de la Unión Europea en el marco de la Directiva 2008/99/CE.

El sujeto imputable por crímenes ambientales es otro elemento central de evolución. Además del individuo (persona natural), sujeto clásico del derecho penal, el derecho penal ambiental retoma del derecho administrativo la imputación de la persona jurídica (persona moral $)^{47}$. Se trata aquí de una evolución del derecho penal clásico que predicaba que la persona jurídica no puede cometer delitos (de la misma manera que no podemos invitarla a desayunar) y la razón de dicha evolución es evidente: en materia ambiental, por regla general, por lo menos una persona jurídica se halla envuelta de una manera u otra en la perpetración de cada crimen ambiental.

En países del common law como Estados Unidos de América, Canadá e Israel, el sometimiento de las personas jurídicas a responsabilidades penales específicas tiene una tradición más importante. Además en Canadá, por ejemplo, los funcionarios públicos pueden ser interpelados penalmente al mismo título que las personas jurídicas de derecho privado ${ }^{48}$. Otros países han reconocido igualmente el principio de la criminalidad de las empresas como China y Japón desde los años noventa ${ }^{49}$,

v. 65, n. 3-4, 1994. en particular, p. 685 ; ESTUPIÑAN-SILVA, R. (Coord.). Report on the Ecocide Project. Paris: Sciences Po Law Clinic, 2013. en particular, p. 78.

46 ESTUPIÑAN-SILVA, R. (Coord.). Report on the Ecocide Project. Paris: Sciences Po Law Clinic, 2013. p. 66 y ss.

47 Desde finales del siglo XX la legislación belga incluyó la responsabilidad civil de las personas jurídicas de modo automático como consecuencia de condenas penales proferidas contra sus empleados, pero la empresa conservaba el derecho a un recurso judicial de repetición contra el empleado penalmente responsable. El derecho administrativo en Suiza, Alemania y Finlandia, consagra de tiempo atrás la posibilidad de condenar al pago de multas a las personas jurídicas, independientemente de las acciones judiciales emprendidas en materia penal contra los individuos que dirigen la empresa. La reforma penal de 2008 (llamado Decreto Wallon de 5 de junio) endureció las sanciones pecuniarias en este sentido. $v$., HENNAU-HUBLET, C.; PIRET, J. M. Belgique. Les crimes contre l'environnement en droit belge. Revue Internationale de Droit Pénal, v. 65, n. 3-4, 1994. en particular, p. 788; PRABHU, M., Avant propos. Les atteintes à l'environnement: problèmes de droit pénal general. Revue Internationale de Droit Pénal, v. 65, n. 3-4, 1994. p. 633, en particular, p. 683.

48 v., MCCHESNEY, A.; MUELLER, T. Canada. Environmental offences in Canada: criminal and regulatory regimes. Revue Internationale de Droit Pénal, v. 65, n. 3-4, 1994, p. 831, en particular, p. 835.

49 CHUN-SI, Y.; SHENG-JUNG, L. Chine. China's treatement
Venezuela desde 1992 y Brasil desde 1998. En el seno de la Unión Europea, luego de la entrada en vigor de la Directiva 2008/99/CE, la inclusión de las personas jurídicas como sujetos imputables de crímenes ambientales devino obligatoria.

Un aspecto interesante de esta evolución jurídica simultánea es que el derecho penal estatal comienza a interesarse por teorías de la responsabilidad internacional penal en contextos de macro-criminalidad, como la empresa criminal conjunta o la teoría del control sobre el crimen. En este sentido, el derecho penal ambiental de los Estados parece tomar conciencia de la existencia de crímenes cometidos de manera sistemática y a gran escala que, como los crímenes internacionales más graves, no son el resultado de una acción indivual y, por el contrario, forman parte de una empresa criminal, creada y estructurada en torno a un objetivo criminal y donde pese a que solo algunos de los individuos ejecutan los actos materiales de los crímenes, la participación y contribución de los demás miembros del grupo es a menudo vital para facilitar la comisión del ilícito y su responsabilidad criminal no es menor ${ }^{50}$.

La noción internacional penal de empresa criminal o de la cadena criminal, sin embargo, no pueden confundirse con la naturaleza y rol de la persona jurídica en los crímenes ambientales ${ }^{51}$. A menudo, la persona jurídica que participa de los crímenes ambientales ha sido creada con un objetivo de lucro legalmente aceptado y su conducta criminal constituye una desviación ilegal de medios para alcanzar el objetivo económico legítimo

of crimes against the environment, Revue Internationale de Droit Pénal, v.65, n. 3-4, 1994. p. 849, en particular, p. 857.

50 TPIY, Appeals Chamber, 15 de julio 2002, The Prosecutor vs. Dusko Tadic "Dule", case IT-94-1-A, sentencia, párrafo 191. Las teorías de responsabilidad internacional penal de los individuos, incluyen sin excepción un extenso análisis del papel de la empresa criminal, bien sea desde el punto de vista de la empresa criminal conjunta (teoría desarrollada por los tribunales ad hoc) o desde el análisis del control sobre el crimen (teoría aplicada en el análisis preliminar de la CPI). Para un análisis comparado podemos sugerir: CLAPHAM, A. Issues of complexity, complicity and complementarity: Nuremberg trials to the dawn of the new International Criminal Court. In: SANDS, P. From Nuremberg to The Hague. The future of International Justice. Cambridge: University Press, 2003, p. 192, p. 30-67; SLIEDREGT, E. von. Parametres of Criminal Responsibility. In: Individual Criminal Responsibility in International Law. Oxford: University Press, 2012. p. 39-57. ESTUPIÑAN-SILVA, R. Teorías de la responsabilidad penal. Derecho Internacional y crimenes de guerra en Colombia, Bogotá: Temis, 2013. p. 155-164.

51 TRICOT, J. Écocrimes et écocide: quels responsables? In: L. NEYRET. Des écocrimes à l'écocide: le droit pénal au secours de l'environnement. Bruselas: Bruylant, 2015, p. 141-163. 
que persigue. Las sanciones a las personas jurídicas que cometen actos criminales no corresponde a las sanciones que pueden ser aplicadas en el marco del crimen organizado a menos que la persona jurídica forme parte de los eslabones de la empresa criminal per se, como instrumento facilitador o de fachada. Dicho de otra manera, en el marco de la lucha contra el crimen organizado, las autoridades pueden encontrarse frente a tráficos ilegales que utilizan personas jurídicas fachada en materia ambiental: tráfico de especies protegidas, tráfico de desechos tóxicos, etc. Pero por regla general, y este es el punto debil de la lucha contra la criminalidad ambiental, las autoridades nacionales se ven confrontadas otro tipo de delincuencia ambiental, es decir, a empresas nacionales y multinacionales perfectamente legales, reconocidas $\mathrm{y}$ apreciadas, frente a quienes no aplican los criterios del derecho internacional penal y contra quienes una investigación penal deviene imposible en la práctica.

En efecto, en el marco de una economía mundializada, el asunto de la responsabilidad penal ambiental suscita en sí mismo el estudio de la implicación de personas jurídicas y funcionarios públicos cómplices. No podemos abstraernos de la constatación del fenómeno de las ecomafias como el obstáculo más importante a la lucha contra la criminalidad ambiental ${ }^{52}$. Así mismo, en el marco de una criminalidad de sistema $a^{53}$, la persecución de un individuo (mera pieza intercambiable) es una tarea ilusoria, mientras que la identificación de su recorrido criminal puede suministrar elementos extremamente valiosos acerca del ilícito (incluida la cadena de mando) y puede tener consecuencias exitosas en la represión de la criminalidad ambiental al más alto nivel.

52 CIAFANI, S. et al. Ecomafia Report 2012. Environmental organized crime in Italy. Available: <http://www.europarl.europa.eu/ document/activities/cont/201207/20120716ATT48981/2012071 6ATT48981EN.pdf>. Access: 17 jan. 2014, fuente original de los Informes Anuales: Disponible: <http://www.legambiente.it/contenuti/comunicati/legambiente-presenta-ecomafia-2013-nomi-enumeri-dell-illegalita-ambientale>. Acceso: 17 jan. 2014

53 En el marco de este estudio, evocamos un enfoque restringido de la macrociminalidad, en el sentido utilizado para estudiar los crímenes internacionales más graves, e identificamos como elementos determinantes: la participación de una multiplicidad de individuos, la existencia de una empresa criminal en el sentido evocado por la jurisprudencia del Tribunal Internacional de la Ex Yugoslavia y, la incapacidad o connivencia estatal. AMBOS, K. Temas de Derecho Internacional Penal y Europeo. Madrid, 2006. Marcial Pons, en particular, p. 535, p. 21 ; BERSMO, M; TRIFFTERER, O. Preamble. In: TRIFFTERER, O. (Ed.). Commentary on the Rome Statute of the International Criminal Court, observer's notes article by article. 2. ed. Munich, 2008. C. H. Beck, Hart, Nomos, en particular, p. 1954, p. 1.
Otro elemento importante en materia penal ambiental se refiere a ciertos medios de defensa o causales de justificación, que no son unánimes entre los Estados. Aquí nos referimos en particular al error de hecho y al error de derecho. El error de hecho puede dar lugar a una responsabilidad por negligencia cuando la conducta punible exige un deber de diligencia y el hecho es atribuible a una falta ${ }^{54}$. El segundo (error de derecho) no forma parte de todos los sistemas penales y esto es sumamente importante debido a la presencia frecuente de tipos penales en blanco en materias ambientales. En efecto, un buen número de infracciones presumen el deber de conocimiento de las normas reglamentarias, pero cuando dichas normas se hallan sometidas a cambios constantes (en el marco de avances científicos, por ejemplo), el error de derecho constituye un medio idóneo de defensa para los crímenes ambientales.

Retendremos finalmente que los crímenes ambientales a menudo no son hechos aislados sino actos de ejecución continuada, donde se ejecutan acciones y omisiones, con un componente de mens rea frecuentemente asociado a la negligencia y no a la intención, donde el autor de la infracción es frecuentemente una persona jurídica. La reacción estatal dependerá en cada caso del bien jurídico que el legislador intenta proteger.

En la práctica, la consagración de infracciones penales autónomas contra el medio ambiente se ha venido generalizando. Una decena de países en Asia y Europa del Este, liderados por Vietnam en 1990 y Rusia en 1996, han incorporado el crimen de ecocidio en sus códigos penales ${ }^{55}$, para referirse a los crímenes ambientales más graves que causan o pueden causar destrucciones masivas del entorno natural y sus componentes.

54 Es el caso, por ejemplo, del derecho penal en Israel. HIRSCH, M. Israël. Criminal Environmental Law in Israel. Revue Internationale de Droit Pénal, v. 65, n. 3-4, 1994. p. 995, en particular, p. 1005.

55 Los países que han adoptado el crimen de ecocidio en el seno de sus sistemas penales son: Armenia (Código Penal de 2003, artículo 394), Bielorrusia (Código Penal de 1999, artículo 131), Georgia (Código Penal de 1999, artículo 409), Kazajstán (Código Penal de 1997, artículo 161), Kirguistán (Código Penal de 1997, artículo 374), Moldavia (Código Penal de 2002, artículo 136), Rusia (Código Penal de 1996, artículo 358), Tayikistán (Código Penal de 1998, artículo 400), Ucrania (Código Penal de 2001, artículo 441) y Vietnam (Código Penal de 1990, artículo 278). v. Disponible: $<$ http://eradicatingecocide.com/overview/existing-ecocide-laws/>. Acceso: 14 set. 2014; NEYRET, L. Libres propos sur le crime d'écocide: un crime contre la sûreté de la planète. In: MÉLANGES, G; MARTIN, J. Pour un droit économique de l'environnement. Frison-Roche, 2013. p. 411, en particular, p. 417. 
Los casos efectivamente juzgados y sancionados en el marco de este tipo penal son sin embargo hechos marginales. Las vacilaciones estatales en este sentido, a nuestro juicio, son un indicador de la necesidad de armonización transnacional, de la circulación de normas y relaciones jurídicas internacionales de los medios de lucha contra la criminalidad ambiental y de las presiones internacionales a que los Estados se hallan sometidos. En este sentido, el proyecto francés sobre el Ecocidio señala en 2015 tres necesidades de adaptación del derecho penal moderno: la internacionalización del derecho sustantivo en materia de infracciones, basada en el elemento de gravedad, la internacionalización de los procedimientos y órganos competentes, en el marco de respeto por los particularismos regionales y nacionales $y$, el fortalecimiento de las infracciones de peligro para hacer frente a la necesidad prioritaria de prevención ${ }^{56}$.

El derecho penal tiene la versatilidad necesaria para combinar la fuerza represiva con el poder disuasivo que se desprende de su eficacia simbólica. Y, en efecto, la lucha contra las infracciones ambientales exige una serie de transformaciones en el estado actual del derecho. En primer lugar, se precisa la integración generalizada del derecho penal como herramienta y con ello la ampliación o unificación de los bienes jurídicos que se entienden protegidos en materia ambiental. En segundo lugar, las infracciones deben ser armonizadas en el espacio, a través de un abordaje transnacional del fenómeno, es decir, el fortalecimiento en la integración de fuentes de derecho público y privado así como de instancias competentes judiciales y quasi-judiciales (eg., los órganos de los tratados) en los niveles nacional, regional e internacional. En tercer lugar, las infracciones así armonizadas deben ser integradas en el tiempo, habida cuenta de la naturaleza de las ofensas, en su mayoría de ejecución continuada, para garantizar una real eficacia en materia de prevención y disuasión, más allá de la represión en sí.

\section{La TRANSNACIONALIZACIÓN DE LOS MEDIOS DE LUCHA}

Desde finales del siglo XX, los avances tecnológicos han permitido a los Estados constatar que ciertos aten-

56 DELMAS-MARTY, M. Préface. In: NEYRET, L. Des écocrimes à l'écocide: le droit pénal au secours de l'environnement. Bruselas: Bruylant, 2015. p. 8-13, en particular p. 13. tados contra el medio ambiente son actos deliberados de carácter extenso y duradero con un impacto grave sobre la vida y la integridad de los seres humanos y el planeta. El artículo 26 del Proyecto de Código de crímenes contra la paz y la seguridad de 1991 definió los crímenes ambientales como "daños de larga duración, extensos y graves contra el medio ambiente" (dommages à long terme, étendus et graves contre l'environnement). Los elementos del proyecto de artículo fueron tomados del artículo 55 del Protocolo I adicional a los Convenios de Ginebra de 12 de agosto de 1949, con un alcance ratione materiae mucho más amplio porque tenía por vocación ser aplicado también en tiempos de $\mathrm{paz}^{57}$. De hecho, los Estados habían acordado limitar los ataques al medio natural en tiempo de guerra y esto desde la Convención de La Haya de $1907^{58}$. Esta prohibición internacional, no obstante, nunca ha gozado de la unanimidad estatal en tiempo de paz, pues el Estado se halla a menudo obligado a someterse a los intereses económicos nacionales e internacionales donde, paradójicamente, la moneda de cambio por excelencia es el medio ambiente.

De toda evidencia, la implementación de herramientas de protección ambiental debe pasar por una fase de armonización para escapar a las presiones y avatares de la política y la economía internacional (A), siempre guardando en mente que las autoridades estatales deben mantenerse como los actores principales en la lucha contra la criminalidad ambiental (B) y que más allá de los medios clásicos del derecho internacional, la circulación de normas y relaciones transnacionales deviene el medio más eficaz de lucha contra la criminalidad ambiental en el corto plazo (C).

\subsection{Vicisitudes internacionales}

Desde 1992, el Informe de la Comisión contra el crimen de Naciones Unidas había alertado contra el vertimiento ilícito de desechos tóxicos y peligrosos, y recomendaba un tratamiento internacional del fenómeno bajo la forma de "modelos de disposiciones penales" 59 .

57 UN, doc. ILC(XLVIII)/DC/CRD.3, Document sur les crimes contre l'environnement, établi par M. Christian Tomuschat, membre de la Commission, Extrait de l'Annuaire de la Commission du droit international, 1996, v. II(1)B, p. 17.

58 eg., Artículo 55 de la Convención (IV) de La Haya relativa a las leyes y costumbres de la guerra terrestre de 18 de octubre de 1907; Artículo 8-2-b-iv del Estatuto de Roma de 1998.

$59 \mathrm{UN}$, doc. ILC(XLVIII)/DC/CRD.3, op. cit., en particular, p. 18. 
En materia doctrinal, en 1995 Gray identificó la noción de ecocidio como una violación graves de los derechos humanos, basándose en características comunes a los crímenes internacionales: la gravedad y el carácter extendido o durable del daño ecológico, las consecuencias transfronterizas, la extensión de las pérdidas y el interés internacional en la sanción de los responsables. Otros autores como Teclaff, se concentraron en el elemento de gravedad para determinar la jurisdicción nacional o internacional competente ${ }^{60}$. También desde la década de los noventas, la doctrina internacional penal de la mano de Bassiouni sugirió cinco criterios aplicables a una política de criminalización internacional: la afectación de un interés internacional, en particular la paz y la seguridad, la afectación de valores comunes a la humanidad incluidas las afrentas a la conciencia de la humanidad, las consecuencias transnacionales de los hechos, el daño causado a las personas o intereses internacionalmente protegidos y, en ausencia de afectación a los intereses internacionales y de la humanidad, la naturaleza misma de la conducta que exige una criminalización internacional. Sobre esta base, y basado en el estudio de 280 tratados, Bassiouni estableció 28 categorías probables de crímenes internacionales, entre ellas: los actos ilícitos contra un cierto número de elementos ambientales protegidos (unlawful acts against certain internationnally protected elements of the environment) ${ }^{61}$.

En 2015, puede constatarse que la lista de la Oficina de Naciones Unidas contra la Droga y el Crimen (UNODC) enlista los crímenes ambientales junto a antiguos crímenes internacionales como la piratería y al lado de fenómenos de criminalidad transnacional emergente como el cybercrimen y el tráfico de órganos ${ }^{62}$. En efecto,

60 GRAY, M. A. The international crime of ecocide. California Western International Law Journal, vol. 26, n. 2, 1995. p. 215; TECLAFF, L. A. Beyond restoration: the case of ecocide. Natural Resources Journal, v. 34, 1994. p. 933 y ss, en particular, p. 953. v., igualmente el interesante estudio de M. Clifford en su versión actualizada: CLIFFORD, M.; EDWARDS, T. Environnmental Crime. 2. ed. Jones \& Bartlett Learning: Burlington, 2012. p. 448, en particular, p. 5.

61 BASSIOUNI, C. Introduction to International Criminal Law. New York: Transnational Publishers, 2003. p. 823, en particular p. 114116.

62 La lucha internacional contra la criminalidad ambiental cuenta con algunas fuentes de derecho bien precisas: Convención sobre el Comercio Internacional de Especies Amenazadas de Fauna y Flora Silvestres (CITES) de 3 de marzo de 1973, el Convenio sobre Diversidad Biológica (CDB) de 5 de junio de 1992, la Convención de Naciones Unidas contra la Delincuencia Organizada Transnacional de 15 de noviembre de 2000, las resoluciones 2001/12, 2003/27 et 2008/25 del Consejo Económico y Social (ECOSOC) y las resoluciones 16/1(2007), 2011/36 y 20/5 (2011) de la Comisión es de público conocimiento de que la mundialización económica ha potenciado la criminalidad ambiental. La dificultad de lucha contra los crímenes ambientales más graves reposa, de hecho, en la incapacidad para conciliar la soberanía de los Estados, la mundialización económica y el ecosistema global ${ }^{63}$. De toda evidencia, la organización del planeta (eg. Biomas transfronterizos de la selva amazónica) no coincide con la organización estatal y sus competencias territoriales exclusivas. La impotencia e insuficiencia de los poderes estatales después de cada atentado criminal contra el medio ambiente son pruebas abrumadoras de esta realidad ${ }^{64}$, sin contar con las dificultades subyacentes en materia de fuentes de derecho y de jurisdicción en el plano internacional ${ }^{65}$.

Dicho esto, en el marco de la Unión Europea no puede negarse la vocación unificadora de la Directiva 2008/99/CE que obliga a los Estados miembros a adoptar medidas penales para hacer frente a los atentados contra el medio ambiente (Artículo 3), hace realidad la persecución contra las empresas (Artículo 6) y toma nota de la dimensión internacional derivada de la gravedad o del carácter transfronterizo de los crímenes ambientales.

de Prevención del Delito y Justicia Penal de Naciones Unidas. v. disponibles: <http://www.unodc.org/unodc/organized-crime/ emerging-crimes.html>. Acceso: 26 jun. 2014

63 Sugerimos leer atentamente dos estudios de jurisprudencia nacional comparada publicados en 2012 y 2014, que muestran como los daños graves contra el medio ambiente están a menudo asociados a la acción económica de empresas transnacionales. v., PIGRAU, A. et al. Legal avenues for EJOs to claim environmental liability. Barcelona, 2012. (EJOLT Report N. 4). p. 98 ; PIGRAU, A. et al. International law and ecological debt Internacional claims, debates and struggles for environmental justice. Barcelona, 2014. (EJOLT Report No. 11). p.128. Los Informes están disponibles en: <www.ejolt.org>. Acceso: 20 jun. 2014.

64 PIGRAU, A. et al. Legal avenues for EJOs to claim environmental liability. Barcelona, 2012. (EJOLT Report N. 4), en particular el Informe 2012 relativo a los instrumentos legales derivados de la competencia territorial (p. 32) y extraterritorial (p. 51-59) del Estado.

65 Sobre la imprecisión de fuentes internacionales que sirvan como fundamento jurídico para que los Estados puedan fundar diligencias penales o civiles de gran impacto en materia de infracciones ambientales que involucran la participación de empresas transnacionales. Esta preocupación es pertinente igualmente en lo que concierne a los usos y abusos de la competencia de los tribunales de Estados Unidos de América. v., MANK, B. Can plaintiffs use multinational environmental treaties as customary international law to sue under the alien tort statute? Utah Law Review, 2007. p. 1085, en particular, p. 1155 y s. Por su parte, Megret señala a justo título las particularidades de los crímenes ambientales transnacionales en cuanto a la mens rea de negligencia grave, la implicación de personas jurídicas y las penas económicas relativas, entre otros. MEGRET, F. The Problem Of An International Criminal Law Of The Environment. Columbia Journal of Environmental Law, v. 36, 2011, p. 195. 
El balance regional del continente americano se mantiene mitigado y menos alentador. Desde hace décadas los países de América Latina se han dotado de una fuerte legislación penal en materia ambiental definiendo el medio ambiente como bien jurídico protegido. El artículo 347-D del Código Penal de Guatemala de 1973, por ejemplo, prevé una pena máxima de quince años de prisión por la explotación, tala, destrucción, comercialización o exportación de recursos de bosques, en casos en que la infracción afecta una especie en vía de extinción o si se lleva a cabo en áreas protegidas o parques nacionales. El Código Penal de Nicaragua de 1974, hace un énfasis especial en los crímenes que afectan las aguas marinas, ríos, cuencas y otras corrientes de agua (Artículo 366) así que sobre el tráfico de especies y contiene elementos agravantes cuando se trata de un tráfico internacional (Artículo 370 y 382). El Código Penal Federal de México de 1931, reformado en 2010, contiene una serie de delitos ambientales en los artículos 414 a 420 relativos a toda actividad de producción, almacenamiento, tráfico, importación o exportación, transporte, abandono, vertido, descarga o toda otra actividad relacionada que pueda atentar contra el medio ambiente y establece penas de prisión de seis meses a nueve años y otras medidas complementarias como multas, suspensión de actividades y licencias, obligación de restitución y muerte civil de individuos y personas jurídicas involucradas (Artículo 421). En Brasil la Ley $\mathrm{n}^{\circ} 9.605$ de 12 febrero 1998, prevé sanciones penales y administrativas derivadas de conductas y actividades nocivas para el medio ambiente en su capítulo V. Dicho apartado contiene una serie de delitos ambientales autónomos referidos a la persona natural y, en particular, el gerente o director de empresa, pero también relativos a la persona jurídica (Artículo 2), con sanciones variadas, que van de la detención de un mes a cuatro años ( $\sin$ beneficio de sustitución de penas) y multas que van de 6 a 16 millones de euros según el crimen (Artículos 2961, 66 y ss., Artículo 75), la expropiación de productos y herramientas ligados a la infracción (Artículo 25), la restricción de derechos (Artículo 8) y la anulación de la personalidad jurídica (artículo 4). En Venezuela, la Ley Penal del Medio Ambiente no 4358, de 3 Enero 1992, ya contemplaba la responsabilidad penal de las personas jurídicas (Artículo 4) y sanciones de la misma naturaleza que las adoptadas años más tarde por la ley brasilera (Artículo 5), incluyendo incluso algunas medidas cautelares para permitir al juez una acción inmediata que le permita evitar un perjuicio irreparable (Artículo 8).
El Código Penal de Colombia (2000), en su Título XI (Delitos contra los recursos naturales y el medio ambiente) Artículos 328-339, es uno de los más recientes y avanzados del continente americano en la materia. Una de sus virtudes es que contiene lo que podríamos llamar "crímenes marco" como el provecho ilícito de los recursos naturales (Artículo 328), la violación de fronteras de explotación (Artículo 329), la manipulación ilícita de micro-organismos nocivos (Artículo 330) y los daños ambientales (Artículo 331), con penas de prisión y multas, que incluyen también los delitos culposos (Artículo $339)^{66}$.

Lo mismo sucede en los Estados Unidos de América que agrupa un conjunto de leyes federales ambientales de naturaleza penal y cuasi-penal, como las infracciones relativas a la contaminación (eg. Act to Prevent Pollution from Ships (APPS), 33 U.S.C. SS 1901-1912, Atomic Energy Act, 42 U.S.C, Artículos 2011-2296, Clean Air Act (CAA), 42 U.S.C. \$S 7401-7671), los atentados a la vida salvaje (eg. Endangered Species Act, 16 U.S.C. Artículo 1531, Bald and Golden Eagle Protection Act (BGEPA), 16 U.S.C, Artículo 668 70, Migratory Bird Treaty Act (MBTA), 16 U.S.C, Artículo 707, Lacey Act, 16 U.S.C, Artículo 3372). Canadá completa el dinamismo jurídico continental en la materia (eg. Canadian Environmental Protection Act, 1999 (CEPA 1999), Wild Animal and Plant Protection and Regulation of International and Interprovincial Trade Act (WAPPRIITA), Canadian Environmental Assessment Act, 2012). Todas las disposiciones jurídicas canadienses contienen contravenciones (misdemeanors) consientes y voluntarias por acción y omisión de las reglas de protección ambiental estatal y federal ${ }^{67}$.

Sin embargo, no puede ocultarse la brecha entre las regulaciones del continente y ausencia de regulación en

66 ESTUPIÑAN-SILVA, R. (Coord.). Report on the Ecocide Project. Paris: Sciences Po Law Clinic, 2013. p. 71-76; sitios oficiales consultados. Guatemala: <http://www.un.org/depts/los/LEGISLATIONANDTREATIES/PDFFILES/GTM_codigo_penal. pdf>; México: <http://www.wipo.int/wipolex/fr/text.jsp?file_ id=199696>; Nicaragua: <http://www.wipo.int/wipolex/fr/text. jsp?file_id=227667>; Colombia: <http://www.alcaldiabogota.gov. co/sisjur/normas/Norma1.jsp?i=6388>; Brasil: <http://www.planalto.gov.br/ccivil_03/leis/19605.htm>; Venezuela: <http://www. minamb.gob.ve/files/ley $\% 20$ penal $\% 20$ del $\% 20$ ambiente/Ley $\% 20$ Penal $\% 20 \mathrm{del} \% 20$ Ambiente.pdf>.

67 ESTUPIÑAN-SILVA, R. (Coord.). Report on the Ecocide Project. Paris: Sciences Po Law Clinic, 2013. p. 68-71; sitios oficiales de Estados Unidos de Amércia: < http://www.justice.gov/ enrd/5469.htm> y de Canadá: <http://www.ec.gc.ca/default. asp?lang $=$ En\&n $=\mathrm{E} 826924 \mathrm{C}-1>$ 
las antillas, en particular, en los países anglófonos del Caribe: Trinidad y Tobago, Bahamas, Santa Lucía, etc. Además, las leyes en el continente americano se mantienen como compartimentos estancos y no existe una voluntad unificadora regional, pues las prioridades de la Organización de Estados Americanos (OEA) y del Mercosur, entre otras instancias regionales, siguen estrechamente ligadas al comercio, a la explotación de recursos naturales y al desarrollo industrial ${ }^{68}$. En consecuencia, la aplicación efectiva de la legislación penal, en vigor en cada Estado, es todo salvo prioritaria.

A nivel global, en materia de ejecución e implementación de sanciones ambientales, conviene mencionar algunas experiencias estatales que muestran cómo una real cooperación transjudicial podría ampliamente contribuir al fortalecimiento de la persecución y sanción de este flagelo. Después de las crisis sobre tratamiento de desechos tóxicos en 2009, Italia mostró una gran disposición de lucha contra la criminalidad ambiental. ${ }^{69}$ Brasil lidera la lucha en materia de criminalidad ligada a la extracción y explotación ilegal de recursos naturales protegidos ${ }^{70} \mathrm{y}$ no puede decirse menos de la experiencia

68 eg. LX Reunión Ordinaria del Sub-Grupo de Trabajo No. 6, Medio Ambiente, MERCOSUR/SGT NO 6/ ACTA No 2/13, de 11 de noviembre de 2013, en particular, páginas 5 y 6 (Proyectos Econormas y Sistema de información ambiental de Mersosur (SIAM)). Disponible en: <www.mercosur.int>; el Punto Focal de las Américas para el fortalecimiento de las capacidades en derecho ambiental y su implementación: Foro Interamericano de Derecho Ambiental (FIDA), la Resolución CIDI/RES.66(IV-O/99, de la Organización de Estados Americanos OEA. Sur: <www.oas.org>. Contatamos, sin embargo, la propuesta reciente en el seno del Mercosur, por parte de la presidencia pro tempore de Venezuela, relativa a la creación de un mecanismo jurídico común para combatir el crimen organizado que podría ser util para combatir la criminalidad ambiental. v. XVI Reunión especializada de Ministerios Públicos del Mercosur, MERCOSUR/REMPM/ACTA No. 02/13, 23 de octubre de 2013. 69 v., UE, European Parliament resolution of 3 February 2011 on the waste crisis in Campania (2012/C 182 E/04). Disponible en: $<$ http://eur-lex.europa.eu/LexUriServ/LexUriServ.do?uri=OJ:C:2 012:182E:0012:0016:EN:PDF>; Italia, Senado y Cámara de Diputados (5 de febrero de 2013): Relazione territoriale sulle attività illecite connesse al ciclo dei rifiuti nella regione Campania (relatori: on. Stefano Graziano e sen. Salvatore Piscitelli). Disponible en: <http://www.senato.it/ service/PDF/PDFServer/BGT/698083.pdf>; MENGOZZI, A. Waste Growth Challenges Local Democracy. The Politics of Waste between Europe and the Mediterranean: a Focus on Italy. California Italian Studies, v. 1, n. 1 2010. ismrg_cisj_8870. Disponible en: $<$ https://escholarship.org/uc/item/53v28242>.

70 eg. Brasil se encuentra a la cabeza de la Organización del Tratado de Cooperación Amazónica de 1978 (OTCA) y del Comité Permanente de la Convención sobre el Comercio Internacional de Especies Amenazadas de Fauna y Flora Silvestres (CITES) de 3 de marzo de 1973. En este marco, el Plan Estratégico 2004-2012 y la agenda 2010 estuvieron centrados en una campaña contra el com- acumulada por los países miembros de la Unión Europea y de la experiencia de China en materia de infracciones ambientales derivadas de la explotación y producción industrial.

En el marco de tales vicisitudes internacionales, la necesidad de una respuesta internacional ambiental bajo la forma de tratados ${ }^{71}$ no pasa por alto la urgencia de fortalecer la acción estatal en materia de persecución y sanciones ${ }^{72}$. Se trata, en efecto, de dos caras de la misma moneda: por una parte, la armonización solo es posible a través de la circulación de normas jurídicas transnacionales a escala regional e internacional y, por otra parte, el pasado, presente y futuro del derecho transnacional no se conciben sin la intermediación estatal pues la implementación de las normas reposa sobre el poder represivo de los Estados.

\subsection{Desafíos estatales}

En 1990, los Estados Unidos de América votaron la creación de un grupo de agentes formados y experimentados para hacer respetar las normas ambientales. Su creación fue apoyada por la oficina de investigaciones y los recursos materiales del FBI (Federal Bureau of Investigation) y la consigna de esta política pública fue clara: "una mejor política en materia de aplicación [de la ley existente] es capaz de disuadir claramente a los infractores"73.

Este ejemplo ilustra nuestro postulado en la materia. Más allá de la creación de nuevas infracciones ambientales hace falta, sobre todo, incrementar los esfuerzos estatales en materia de aplicación efectiva del derecho penal existente. El papel de los responsables políticos es esencial para obtener resultados, pues ningún derecho penal puede ser eficaz si persiste una cultura de impunidad frente a los crímenes a que se refiere. El papel de los expertos científicos y su asistencia técnica en calidad

ercio ilegal y la preservación de los saberes ancestrales, buscando en particular la protección de las especias de flora y fauna de la cuenca amazónica, v. Sitio oficial OTCA. Disponible en: <http://otca. info/portal/apresentacao.php? $\mathrm{p}=$ agd $>$.

71 Evocada y ampliamente justificada en la obra colectiva Ecocidio v., NEYRET, L. Partie II: Projet de Conventions internationales. In: DES ÉCOCRIMES à l'écocide: le droit pénal au secours de l'environnement. Bruselas: Bruylant, 2015. p. 261-301.

72 BERAT, L. Defending the right to a healthy environment: toward a crime of geocide in international law. Boston University International Law Journal, 1993, p. 327, en particular, p. 343.

73 PRABHU, M. Rapport general: les atteintes à l'environnement: problèmes de droit pénal general. Revue Internationale de Droit Pénal, v. 65, n. 3-4, 1994. en particular, p. 696. 
de peritos o consultantes de la administración de justicia tampoco puede ser pasado por alto. En el asunto Saramaka vs. Surinam $(2007)^{74}$, por ejemplo, los cartógrafos suministraron elementos de prueba de gran valor para establecer el alcance del daño ambiental provocado a las comunidades tribales como consecuencia de la actividad económica transnacional. La condena contra la multinacional AngloGold Ashanti en Sudáfrica en los casos de silicosis (Thembekile Mankayi vs. AngloGold Ashanti Ltd (2011)) $)^{75}$ no habría sido posible sin los avances científicos capaces de probar el nexo entre los productos utilizados en minería para la extracción del oro y las enfermedades contraídas por los trabajadores. En este mismo orden de ideas, el caso María Aguinda et al. vs. Cheuron Corporation (2012) ${ }^{76}$ se centró principalmente entorno a la fiabilidad de los peritajes que fueron discordantes sobre los efectos de la actividad petrolera sobre la salud de las comunidades. La calidad de los expertos, su independencia frente al poder de la empresa juzgada y los recursos disponibles para efectuar los análisis fueron algunas de las consideraciones centrales en materia de credibilidad del peritaje en sí mismo y su contribución a la lucha contra la criminalidad ambiental.

El caso Chevron antes citado también muestra la urgencia de nuevas herramientas transnacionales de lucha contra la impunidad derivada de la inejecución de sentencias $^{77}$. En efecto, las sanciones en derecho penal buscan siempre la prevención, la represión y la disuasión, sin descartar las medidas de reparación que ocupan un lugar privilegiado cuando se trata de sancionar personas jurídicas por daños ambientales graves. De ahí precisamente se desprende la necesidad de armonización transnacional. La inejecución de sanciones es a menudo una consecuencia de las presiones ejercidas por el capital transnacional al endurecimiento de las políticas públicas de Estados usualmente considerados como paraísos de impunidad ambiental. Una vez más nos en-

74 Corte IDH, 28 de noviembre de 2007, Pueblo Saramaka c. Suriname, sentencia de Excepciones Preliminares, Fondo, Reparaciones y Costas.

75 Corte Constitucional de Sudáfrica, 3 de marzo de 2011, Thembekile Mankayi vs. AngloGold Ashanti Ltd. (silicosis lawsuit), sentencia.

76 Corte Provincial de Justicia de Sucumbíos (Ecuador), 14 de febrero de 2011, María Aguinda et al vs. Chevron Corporation, No. 0022003, Sentencia.

77 MARTIN-CHENUT, K.; PERUSSO, C. L'affaire Chevron/Texaco et l'apport des projects de Conventions Ecocrimes et Ecocide. In: NEYRET, L. Des écocrimes à l'écocide: le droit pénal au secours de l'environnement. Bruselas: Bruylant, 2015. p. 67-86, en particular p. 83. contramos frente a la dicotomía entre lo jurídicamente relevante y lo socialmente prioritario. La alternativa a este tipo de frenos jurídicamente válidos pero socialmente inaceptables se encuentra en la armonización de las normas ambientales. La cooperación reforzada y/o la vía de los tratados son herramientas eficaces que, de contera, impiden todo tipo de alegaciones de dumping ambiental en materia comercial. Efectivamente, más allá de la teoría sancionatoria, queda aún un largo camino por recorrer en lo que concierne a la ejecución de penas pronunciadas por los Estados contra gigantes económicos ${ }^{78}$. La pena promedio impuesta en la práctica no representa más que una fracción mínima del máximo establecido. La administración de justicia estatal hace gala de una gran clemencia frente a los autores de infracciones ambientales, en particular, frente a aquellos que cometen la infracción por primera vez y, principalmente, cuando se trata casos sensibles que afectan intereses económicos o políticos ${ }^{79}$. Como consecuencia paradójica obtenemos que es más probable que infracciones ambientales menores sean juzgados con severidad excesiva y que los grandes atentados contra el medio ambiente permanezcan impunes, amparados por normas preferenciales destinadas al capital transnacional.

Conviene interrogarse igualmente sobre el papel del poder judicial estatal, sus temores y desafíos. En el estado actual del derecho penal ambiental en el mundo, la competencia territorial se halla en manos del juez nacional sea este penal o administrativo ${ }^{80}$. No obstante, como en otros contextos de macro-criminalidad, el poder judicial se encuentra sometido a un sinnúmero de presio-

78 El caso Chevron/Texaco es uno de los últimos ejemplos sangrantes de la impotencia de los Estados para ejecutar sanciones judiciales cuando un "gigante transancional" que se encuentra de facto bajo la protección una potencia estatal, es condenado por infracciones ambientales. v. supra; Corte Provincial de Justicia de Sucumbíos (Ecuador), 15 de octubre de 2012, María Aguinda et al vs. Chevron Corporation, No. 21100-2003-0002, orden de congelamiento de fondos; Corte Suprema de Justicia de Argentina, 4 de junio de 2013, Maria Aguinda Salazar vs. Chevron Corporation, medidas cautelares (congelación de fondos, medidas provisionales).

79 A cerca del papel de la realpolitik v. FOSTER, P. Climate Torts and Ecocide in the Context of Proposals for an International Environmental Court. City College of New York, 2011, en particular, p. 95.

80 La noción de territorio internacionalmente aceptada se extiende igualmente al mar territorial, el especio aéreo, y la zona de pezca, la zona económica exclusiva y la plataforma continental así como a las embarcaciones y aeronaves que porten la bandera del país donde quiera que ellos se encuentren, en virtud de la Convención de Naciones Unidas sobre el Derecho del Mar de 10 de diciembre de 1982 . 
nes políticas legales e ilegales que buscan su inacción ${ }^{81}$. En la práctica, el juez de la criminalidad ambiental no puede administrar justicia sin la estrecha colaboración del poder ejecutivo. Las políticas públicas y la voluntad de los órganos del Estado devienen prioritarias pues la experticia de cada poder público completa y fortalece las deficiencias mutuas existentes. Además, solo una comunicación fluida y centrada sobre las prioridades ambientales, permite la acción eficaz en un ámbito en que los intereses económicos, sociales y ambientales pueden ser determinantes y a menudo contradictorios ${ }^{82}$. Pero ¿cómo hacer posible la lucha contra la criminalidad ambiental sin 'perder' ventajas competitivas en el mercado del capital transnacional? La comprensión de la naturaleza transnacional del problema parece ser el punto de partida para identificar soluciones probables.

\subsection{Horizontes transnacionales}

El alcance y la complejidad de los crímenes ambientales exigen un enfoque especializado, que sobrepasa las herramientas tradicionales del derecho penal, es decir, un enfoque cooperativo del derecho, de las autoridades civiles y científicas del medio ambiente. Herramientas extrajurídicas como los estudios previos de impacto ambiental y social sobre los grandes proyectos económicos y de infraestructura, juegan un rol preventivo no despreciable en materia de criminalidad ambiental ${ }^{83}$. En efecto, si el derecho administrativo ejercía el control total de las infracciones ambientales hasta finales del siglo $\mathrm{XX}$, el lugar del derecho penal es indiscutible a la hora actual $^{84}$.

81 Creemos que el análisis utilizado para describir los contextos en los cuales la administración de justicia nacional juzga crímenes de guerra pueden ser aplicados al enjuiciamiento de crímenes ambientales graves, en particular, los límites derivados de la disimulación de los elementos materiales, de los autores, la ejecución defectuosa de las sanciones y los factores económicos, sociales y políticos que inciden directamente sobre la capacidad del operador judicial para administrar justicia., v. ESTUPIÑAN SILVA, R. Repercusión de la jurisdicción nacional en materia de crímenes de guerra. Derecho Internacional y crímenes de guerra en Colombia. Bogotá: Temis, 2013. p.367, en particular p. 217-251.

82 v. Actes de la Réunion constitutive du comité sur l'environnement de l'Association des cours judiciaires suprêmes francophones AHJUCAF, Porto-Novo (Bénin), 26-27 de junio de 2008, en particular, p. 403.

83 Esta es una exigencia en el marco interamericano de derechos humanos. v. Corte IDH, 28 de noviembre de 2007, Pueblo Saramaka vs. Surinam, supra, parágrados 129, 139 y 143.

84 ESTUPIÑAN-SILVA, R. (Coord.). Report on the Ecocide Project. Paris: Sciences Po Law Clinic, 2013. p. 66. Esta fue una de las con-
¿Existe entonces una práctica general de los Estados según la cual las infracciones ligadas al medio ambiente son penalmente sancionadas? En todos los casos, la vía penal no es ciertamente la única emprendida por las autoridades. La ampliación de las categorías de bienes protegidos por el derecho penal no es suficiente en sí misma para parar la crisis ecológica. Los estudios existentes en materia de impacto de las leyes ambientales, incluidas las normas penales, confirman esta afirmación ${ }^{85}$.

Estamos convencidos que solo un enfoque holístico a la vez nacional, regional e internacional, es decir, un enfoque transnacional puede hacer frente a la criminalidad ambiental del siglo XXI. Dicho enfoque debe incluir la dimensión penal sin limitarse exclusivamente a ella, y debe estar profundamente anclado en una política pública dirigida al fortalecimiento de las institucionales nacionales y la participación reforzada de la sociedad civil. El conjunto de medios y métodos así reunidos conseguiría un seguimiento detallado del impacto de la legislación ambiental y de la educación social y ambiental, con el fin de combatir eficazmente esta forma de criminalidad. De otro modo, la criminalidad ambiental va a continuar actuando allí donde la impunidad sea asegurada, bien sea por falta de voluntad de los Estados o por su incapacidad a llevar a término verdaderas acciones judiciales.

La respuesta internacional por la vía de tratados exige un acuerdo acerca de prohibiciones absolutas, en función de los elementos de los crímenes internacionales que se hallan íntima e indefectiblemente ligados al elemento de gravedad $^{86}$. A la hora actual no creemos

clusiones del Programa de crímenes ambientales de INTERPOL en el marco de su I Conferencia internacional para el fortalecimiento y la aplicación del derecho ambiental: INTERPOL-UNEP International Conference on Environmental Compliance and Enforcement (Nairobi, 6 de noviembre de 2013). Disponible en: < http://www. iisd.ca/interpol/iecec/>. Acceso: 20 jun. 2014.

85 eg., UNEP. América Latina y Caribe, Diagnóstico. Propuesta de Ley básica para la Protección Ambiental y la Promoción del Desarrollo Sostenible para los países de Centroamérica y Panamá. México, 1993; Directiva 2008/99/CE de la Unión Europea, considerando 3.

86 Aunque algunos autores defienden el carácter internacional per se de las ofensas ambientales, nosotros preferimos acogernos a los métodos de identificación del derecho internacional penal a partir de los elementos de los crímenes. Sobre la naturaleza internacional autónoma de los crímenes ambientales v, BEAUVAIS, P. Les limites de l'internationalisation du droit pénal de l'environnement. In: NEYRET, L. Des écocrimes à l'écocide: le droit pénal au secours de l'environnement. Bruselas: Bruylant, 2015. p. 3-18, en particular p. 6. Acerca de los elementos de los crímenes internacionales v., entre muchos otros: BASSIOUNI, C. Introduction to International Criminal Law. New York: Transnational Publishers, 2003. p. 114 y 116; 
poder hablar stricto sensu de debilidades de los crímenes internacionales contra medio ambiente porque no existen. Es preciso recordar en este sentido que la existencia de un crimen internacional reconocido como tal en el siglo XXI depende de dos factores concurrentes de derecho sustantivo (infracción internacional) y de procedimiento (jurisdicción internacional competente) ${ }^{87}$. Los rudimentos del derecho sustantivo internacional penal del medio ambiente existen, en su mayoría ligados a la contaminación intencional o negligente durante la cadena de producción industrial: exploración, explotación, saneamiento y desechos ${ }^{88}$. En su evolución, la ausencia de criterios comunes en materia de estructura y elementos de los crímenes ambientales, ha contribuido a penalizar lo accesorio y perseguir los pequeños infractores, al mismo tiempo que banaliza ciertas conductas al origen de serios atentados ambientales y se muestra indulgente frente a las grandes inversiones ${ }^{89}$. No obstante, la ausencia de jurisdicción internacional competente evita que podamos referirnos a crímenes internacionales contra el medio ambiente en sí. Existe, creemos, un derecho transnacional penal del medio ambiente, que se halla en vías de armonización en materia sustantiva y que no cuenta con herramientas eficaces en materia procesal. Es de amplio conocimiento que el ejercicio restrictivo de la soberanía nacional, la ausencia de mecanismos de cooperación reforzada en materia ambiental y la consolidación de paraísos de impunidad ambiental bajo control de facto de las empresas transnacionales, son obstáculos reales que impiden la eficacia de la persecución y

ESTUPIÑAN-SILVA, R. Estructura de los crímenes en el Estatuto de Roma. Revista del Instituto Nacional de Ciencias Penales de México, México, v. 2, p. 11-30, 2011; ESTUPIÑAN-SILVA, R. L'activation de la compétence de la Cour pénale internationale et les développements concernant le rôle de la gravité. In: DIZDAREVIC, A.; KOUDÉ, R. Les droits de l'homme: défis et mutations. Paris: L'Harmattan, 2013. p. 51-65.

87 ESTUPIÑAN-SILVA, R. Principios que rigen la Responsabilidad Internacional Penal por crímenes internacionales. Anuario Mexicano de Derecho Internacional AMDI, v. 12, 2012. p. 133-173; ESTUPIÑAN-SILVA, R. Estructura de los crímenes en el Estatuto de Roma. Revista del Instituto Nacional de Ciencias Penales de México, México, v. 2, p. 11-30, 2011.

88 ASCENCIO, H. Les infractions en matière de pollution. In: ASCENSIO, H.; DECAUX, E.; PELLET, A. Droit international pénal. 2. ed. París: Pedone, 2012. p. 1280, en particular, p. 391.

89 Ver en este sentido los interesantes aportes a la construcción de un derecho penal internacional sustantivo en materia ambiental. D'AMBROSSIO, L. Vers un droit pénal commun de l'environnement: critères et techniques d'incriminnation, In: NEYRET, L. Des écocrimes à l'écocide: le droit pénal au secours de l'environnement. Bruselas: Bruylant, 2015. p. 87-107, en particular pp. 88 y 89. la sanción, aún en presencia de la norma ${ }^{90}$.

La academia francesa propuso en 2015 una respuesta internacional a la criminalidad ambiental a través de la firma de dos tratados posibles: Ecocrímenes y Ecocidio. El tratado Ecocrímenes apunta a la identificación de infracciones graves transfronterizas, comunes a los Estados firmantes, con miras a la internacionalización de la ilicitud de la conducta y su control por medios normativos y de diplomacia internacional. El elemento central de las infracciones propuestas es el riesgo cierto para el equilibrio natural del planeta, mediado por el estudio del elemento de gravedad, común a los crímenes internacionales. A esta dimensión objetiva de protección del medio ambiente (artículo 3) como bien jurídico autónomo, se suma una dimensión subjetiva que protege a la humanidad en el sentido presente y futuro y busca la ilicitud internacional de conductas que puedan atentar durablemente contra la vida humana y la integridad, incluida la salud (artículo 4). Se trata de retomar un binomio (seguridad internacional - salud humana) que forma parte de los antecedentes remotos de los crímenes ambientales desde el proyecto de Crímenes contra la paz y la seguridad de 1991. La propuesta de tratado de Ecocidio, por su parte, está centrada en la protección de la seguridad del planeta y en la sanción de actos intencionales cometidos en el marco de una acción generalizada y sistemática (artículo 2), evocando los componentes estructurales del artículo 7 del Estatuto de Roma sobre los crímenes de lesa humanidad.

Las dos propuestas coinciden en la presencia de elementos extrajurídicos del tipo penal como la noción de peligrosidad de una sustancia, el carácter salvaje y/o protegido de una especie animal o vegetal, entre otros. Una consecuencia del uso de estos elementos extrajurídicos es que la definición de las infracciones puede cambiar en función en función de nuevas herramientas científicas capaces de diagnosticar la magnitud de la amenaza contra el medio ambiente o de la transformación de una normativa interna. La creación de infracciones de peligro, los tipos penales abiertos o en blanco,

90 A nuestro entender, los paraísos de impunidad ambiental están más ligados a las presiones que padecen los pequeños Estados y que son ejercidas por capitales transnacionales y sus empresas, en ocasiones apadrinadas por poderosos Estados. Aunque no descartamos otros elementos, como los egoísmos estatales y los deseos de desarrollo o mejora de la situación económica local por la vía de la venta de servicios ambientales, creemos que estas razones están más ligadas a una retórica internacional que a la realidad geopolítica de los Estados. 
la presencia de analogías, la indeterminación del bien jurídico protegido (hombre-naturaleza), la imputabilidad de la persona jurídica ${ }^{91}$ son elementos ajenos y/o extremamente excepcionales en el derecho penal de los Estados y exigen ser cuidadosamente estudiados y equilibrados. Por una parte la seguridad del planeta es un interés mayor de la humanidad y, sin embargo, el principio de legalidad y sus componentes esenciales (lex certa, stricta, proevia), es la piedra angular sobre la que se funda el derecho penal y el derecho internacional penal desde finales del siglo XX ni hace ni puede hacer abstracción de él ${ }^{92}$.

Las prácticas requeridas en materia de control de la criminalidad ambiental más grave, se refieren de suyo al control de la criminalidad de las empresas (personas jurídicas de derecho privado nacional e internacional) en materia ambiental. En consecuencia, en materia de implementación ninguna propuesta puede ignorar la urgencia de la transancionalización de normas y relaciones jurídicas a través de la cooperación reforzada de los órganos de los Estados.

En función de la naturaleza de la empresa, de la gravedad de la conducta, de los bienes jurídicos protegidos, de la reincidencia ${ }^{93}$, entre otros elementos clásicos de graduación de las penas, las autoridades competentes podrán escoger las sanciones pertinentes sin pasar por alto los derechos de la sociedad como víctima principal, en términos de verdad, justicia, reparación y no repetición frente a los actos ofensivos. Al igual que la protección de los derechos humanos, el respeto de las normas ambientales ha venido imponiéndose en el discurso de las empresas como parte de la agenda de buenas prácticas, responsabilidad social de las empresas (compliance), y

91 Las analogías (prohibidas en derecho penal), así como el uso de tipos penales abiertos, son alternativas evocadas en el marco de la evolución hacia un modelo de derecho penal de anticipación que pese a sus virtudes, evoca en el autor todos los riesgos del debilitamiento en la seguridad jurídica de los delitos y las penas señalados desde Beccaria. Sobre la propuesta de modelo de anticipación: FRONZA, E.; GUILLOU, N. Vers une définition du crime international d'écocide. In: NEYRET, L. Des écocrimes à l'écocide: le droit pénal au secours de l'environnement. Bruselas: Bruylant, 2015. p. 127-140, en particular pp. 136-138.

92 v., por ejemplo, ESTUPIÑAN-SILVA, R. Principios que rigen la Responsabilidad Internacional Penal por crímenes internacionales. Anuario Mexicano de Derecho Internacional AMDI, v. 7, 2012. p. 133-173, en particular p. 148 a 151.

93 NIETO-MARTÍN, A. Justice restauratrice et sanctions pour un droit pénal international de l'environnment. In: NEYRET, L. Des écocrimes à l'écocide: le droit pénal au secours de l'environnement. Bruselas: Bruylant, 2015. p. 183-202, en particular p. 189 y 190. como un desafío para la imagen de la marca.

La creación de una jurisdicción internacional competente en materia de crímenes ambientales, es poco probable y no necesariamente pertinente. La cooperación transjudicial, por otra parte, es una solución de corto y mediano plazo que tiene mayor impacto en materia de eficacia y de costo-beneficio. La migración de las normas y los conceptos por medio de la comunicación transjudicial en materias de derecho constitucional y de derecho internacional de los derechos humanos es un hecho ampliamente conocido y documentado por la doctrina ${ }^{94}$. Ahora bien, la cooperación judicial forma parte de los acuerdos de intenciones de todas las organizaciones jurídicas internacionales, bajo la forma de tratados y/o de memorandos de entendimiento como el que fue firmado entre la Organización de Estados Americanos y la Corte Penal Internacional en $2012^{95}$. Las organizaciones regionales, cuentan con convenios y cláusulas de cooperación interinstitucional suscritas a todos los niveles de las que Interpol se sirve a menudo en su lucha contra el crimen organizado. La cooperación en fases previas, de prevención e investigación es marginal, no obstante las herramientas disponibles.

Una cooperación transnacional eficaz puede actuar antes de la infracción, a través de un sistema de alertas tempranas como el que se utiliza en materia de derechos humanos, durante el proceso judicial a través de la ejecución de medidas cautelares (embargos, congelación de fondos, prohibición de liquidación, extradición, etc.) y del intercambio fluido de la información disponible así como de la ejecución de investigaciones al extranjero, entre otras herramientas existentes.

94 Para Slaughter, por ejemplo, la comunicación transjudicial se origina en la necesidad de persuadir o convencer a través de argumentos, como medio para reforzar la posición del juez o transformar la linea jurisprudencial en vigor, y varía enormemente en cuanto a sus jerarquías (verticales, horizontales, mixtas), funciones (legitimidad, efectividad, aceptación de estándares internacionales, fertilización mutua, deliberación colectiva) y nivel de compromiso mutuo (diálogo, monólogo, comunicación interpuesta). v, SLAUGHTER, A. M. A Typology of Transjudicial Communication. Richmond Law Review, v. 29, 1994. p. 101-122; SLAUGHTER, A. M. A Global Community of Courts. Harvard International Law Journal, v. 44, 2003. p. 191 y ss. Ver, en el mismo sentido, GISBERT, R. Bustos. XV proposiciones generales para una teoría de los diálogos judiciales. Revista Española de Derecho Constitucional, 2012. p. 20; BURGORGUELARSEN, L. El diálogo judicial: Máximo desafío de los tiempos modernos, México: Porrúa, 2013.

95 OAS/ICC (Memorandum of understanding on cooperation) 25 April 2012, 4 pp. 
Estos y otros medios están actualmente al alcance de los Estados en la lucha contra la criminalidad ambiental, sin desconocer otras soluciones estructurales de naturaleza supraestatal que pueden tardar un poco más en ser puestas en marcha ${ }^{96}$. Todos los medios disponi-

96 La vía de los tratados es defendida a lo largo de toda la obra dirigida por el profesor L. Neyret, cuyo punto culminante es la presentación de convenios tipo. No obstante, ninguno de los autores descarta la importancia de otras alternativas como el arreglo pacífico de diferendos, el arbitraje, los procedimientos de no respecto o no conformidad ante órganos del tratado y la cooperación transancional reforzada aquí defendida. v. por ejemplo: ROBACZEWSKI, C. L'entraide pénale internationale en matière de criminalité environnementale. In: NEYRET, L. Des écocrimes à l'ecocide: le droit pénal au secours de l'environnement. Bruselas: Bruylant, 2015. p. 223-239; HENRY, S. La contribution des mécanismes internationaux de règlement des différends à la pénalisation des atteintes à l'environnement. In: NEYRET, L. Des écocrimes à l'écocide: le droit pénal au secours de l'environnement. Bruselas: Bruylant, 2015. p. 241259; NEYRET, L. Partie II: Projet de Conventions internationales. In: NEYRET, L. Des écocrimes à l'écocide: le droit pénal au secours de l'environnement. Bruselas: Bruylant, 2015, p. 261-301. bles son importantes a la hora de conciliar la justiciabilidad ambiental pues, en el estado actual del derecho, lo que es jurídicamente relevante dista mucho de lo que es socialmente, como lo deja patente una vez mas el caso Chevron/Texaco, donde la ejecución de sentencias se encuentra in fine a la merced de tecnicismos y ataques jurídicos extraterritoriales. ${ }^{97}$

97 La creación de empresas nacionales de apariencia jurídica autónoma por parte de las empresas multinacionales es otro medio jurídico que bloquea la sanción al más alto nivel (eg., caso Trafigura en Costa de Marfil). En otros casos, las consideraciones procesales de soberanía territorial se imponen sobre consideraciones de impacto ambiental (eg., caso Erika entre Francia y Gran Bretaña). Para un estudio de los problemas de jurisdicción en materia ambiental v., C. Solis, Juger des crimes environnementaux internationaux: approche jurisdictionnelle et institutionnelle, in L. Neyret (dir.) Des écocrimes à l'écocide : le droit pénal au secours de l'environnement, Bruselas, Bruylant, 2015, pp. 203-221. 
Para publicar na Revista de Direito Internacional, acesse o endereço eletrônico www.rdi.uniceub.br ou www.brazilianjournal.org.

Observe as normas de publicação, para facilitar e agilizar o trabalho de edição. 